\title{
Surgical versus conservative interventions for treating ankle fractures in adults (Review)
}

Donken CCMA, Al-Khateeb H, Verhofstad MHJ, van Laarhoven CJHM
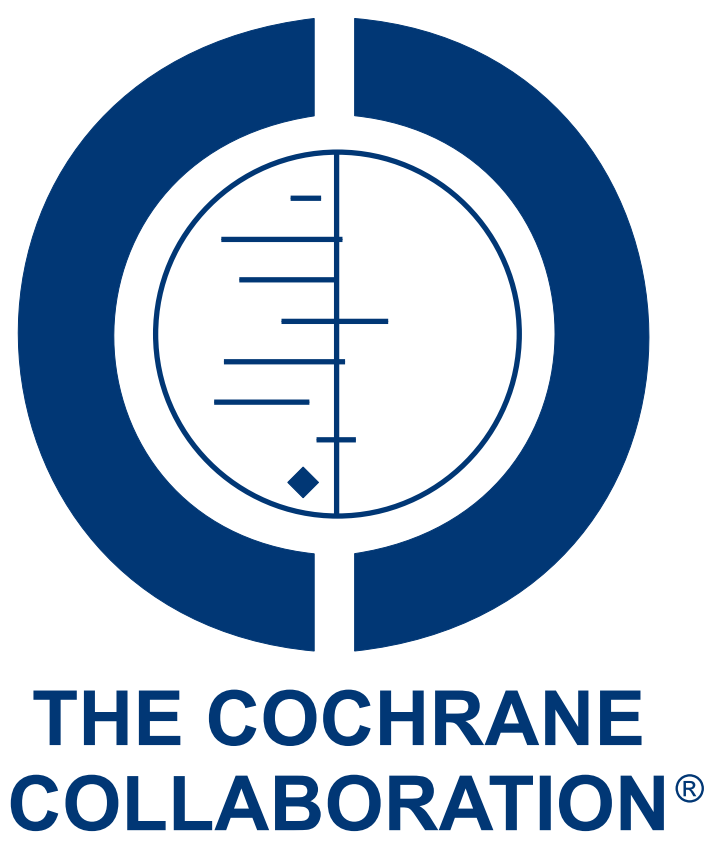

This is a reprint of a Cochrane review, prepared and maintained by The Cochrane Collaboration and published in The Cochrane Library 2012, Issue 8

http://www.thecochranelibrary.com

\section{WILEY}

Surgical versus conservative interventions for treating ankle fractures in adults (Review)

Copyright $\odot 2012$ The Cochrane Collaboration. Published by John Wiley \& Sons, Ltd. 
TABLE OF CONTENTS

HEADER . . . . . . . . . . . . . . . . . . . . . . . . . . . . . . . . . . . . . . . 1

ABSTRACT . . . . . . . . . . . . . . . . . . . . . . . . . . . . . . . . . . . . . . .

PLAIN LANGUAGE SUMMARY . . . . . . . . . . . . . . . . . . . . . . . . . . . . . . . . . . . . 2

BACKGROUND . . . . . . . . . . . . . . . . . . . . . . . . . . . . . . . . . . . . . 2

OBJECTIVES . . . . . . . . . . . . . . . . . . . . . . . . . . . . . . . . . . . . . . . . . . . . .

METHODS . . . . . . . . . . . . . . . . . . . . . . . . . . . . . . . . . . . . . . . .

RESULTS . . . . . . . . . . . . . . . . . . . . . . . . . . . . . . . . . . . . 6

Figure 1. . . . . . . . . . . . . . . . . . . . . . . . . . . . . . . . . . . . 8

Figure 2. . . . . . . . . . . . . . . . . . . . . . . . . . . . . . . . . . . . . . . . . . . 9

DISCUSSION . . . . . . . . . . . . . . . . . . . . . . . . . . . . . . . . . . . . .

AUTHORS' CONCLUSIONS . . . . . . . . . . . . . . . . . . . . . . . . . . . . . . . . . . . . 11

ACKNOWLEDGEMENTS . . . . . . . . . . . . . . . . . . . . . . . . . . . . . . . . . . . . . . . .

REFERENCES . . . . . . . . . . . . . . . . . . . . . . . . . . . . . . . . . . . . . . . 12

CHARACTERISTICS OF STUDIES . . . . . . . . . . . . . . . . . . . . . . . . . . . . . . . . . . . . .

DATA AND ANALYSES . . . . . . . . . . . . . . . . . . . . . . . . . . . . . . . . . . . 25

Analysis 1.1. Comparison 1 Surgical versus conservative treatment, Outcome 1 Complaints of symptoms (pain, restricted range of ankle motion, unsteadiness, swelling) and walking difficulties at 7 years. . . . . . . . . . . . . . . . 26

Analysis 1.2. Comparison 1 Surgical versus conservative treatment, Outcome 2 Functional or combined scores. $\quad$. $\quad$. 27

Analysis 1.3. Comparison 1 Surgical versus conservative treatment, Outcome 3 Pain scores (VAS: assume maximum of 100: worst) at mean of 27 months. . . . . . . . . . . . . . . . . . . . . . . . . . . . . . . . . . . . . . 28

Analysis 1.4. Comparison 1 Surgical versus conservative treatment, Outcome 4 Adverse events. . . . . . . . . . . . $\quad 28$

Analysis 1.5. Comparison 1 Surgical versus conservative treatment, Outcome 5 Functional impairment at 20 weeks. . 30

Analysis 1.6. Comparison 1 Surgical versus conservative treatment, Outcome 6 Differences in range of motion (injured ankle - other ankle). . . . . . . . . . . . . . . . . . . . . . . . . . . . . . . . 31

Analysis 1.7. Comparison 1 Surgical versus conservative treatment, Outcome 7 Radiological results: non-union and malunion. . . . . . . . . . . . . . . . . . . . . . . . . . . . . . . . . . . . 32

Analysis 1.8. Comparison 1 Surgical versus conservative treatment, Outcome 8 Radiological signs of osteoarthritis. . $\quad 33$

Analysis 1.9. Comparison 1 Surgical versus conservative treatment, Outcome 9 Length of hospital stay (days). . . . 34

APPENDICES . . . . . . . . . . . . . . . . . . . . . . . . . . . . . . . . . . . . . 34

HISTORY . . . . . . . . . . . . . . . . . . . . . . . . . . . . . . . . . . . . . . . 36

CONTRIBUTIONS OF AUTHORS . . . . . . . . . . . . . . . . . . . . . . . . . . . . . . . . . . . 36

DECLARATIONS OF INTEREST . . . . . . . . . . . . . . . . . . . . . . . . . . . . . . . . . . . . 36

SOURCES OF SUPPORT . . . . . . . . . . . . . . . . . . . . . . . . . . . . . . . . . . . . . . . . . . . . . . .

INDEX TERMS . . . . . . . . . . . . . . . . . . . . . . . . . . . . . . . . . . . . . . . . . . . . . . .

Surgical versus conservative interventions for treating ankle fractures in adults (Review)

Copyright $\odot 2012$ The Cochrane Collaboration. Published by John Wiley \& Sons, Ltd. 


\title{
[Intervention Review] \\ Surgical versus conservative interventions for treating ankle fractures in adults
}

\author{
Christian CMA Donken ${ }^{1}$, Hesham Al-Khateeb ${ }^{2}$, Michael HJ Verhofstad ${ }^{3}$, Cornelis JHM van Laarhoven ${ }^{4}$ \\ ${ }^{1}$ Department of General and Trauma Surgery, Radboud University Nijmegen Medical Center, Nijmegen, Netherlands. ${ }^{2}$ Department \\ of Trauma \& Orthopaedics, Princess Alexandra Hospital, Harlow, UK. ${ }^{3}$ Department of General and Trauma Surgery, Saint Elisabeth \\ Hospital, Tilburg, Netherlands. ${ }^{4}$ Department of Surgery, Radboud University Nijmegen Medical Center, Nijmegen, Netherlands
}

Contact address: Christian CMA Donken, Department of General and Trauma Surgery, Radboud University Nijmegen Medical Center, PO Box 9101, Nijmegen, 6500 HB, Netherlands. christiandonken@hotmail.com.

Editorial group: Cochrane Bone, Joint and Muscle Trauma Group.

Publication status and date: New, published in Issue 8, 2012.

Review content assessed as up-to-date: 6 May 2012.

Citation: Donken CCMA, Al-Khateeb H, Verhofstad MHJ, van Laarhoven CJHM. Surgical versus conservative interventions for treating ankle fractures in adults. Cochrane Database of Systematic Reviews 2012, Issue 8. Art. No.: CD008470. DOI: 10.1002/14651858.CD008470.pub2.

Copyright (C) 2012 The Cochrane Collaboration. Published by John Wiley \& Sons, Ltd.

\begin{abstract}
A B S T R A C T
Background

The annual incidence of ankle fractures is 122 per 100,000 people. They usually affect young men and older women. The question of whether surgery or conservative treatment should be used for ankle fractures remains controversial.
\end{abstract}

Objectives

To assess the effects of surgical versus conservative interventions for treating ankle fractures in adults.

\section{Search methods}

We searched the Cochrane Bone, Joint and Muscle Trauma Group Specialised Register, the Cochrane Central Register of Controlled Trials (The Cochrane Library, 2012 Issue 1), MEDLINE, EMBASE, CINAHL and the WHO International Clinical Trials Registry Platform and Current Controlled Trials. Date of last search: 6 February 2012.

\section{Selection criteria}

Randomised and quasi-randomised controlled clinical studies comparing surgical and conservative treatments for ankle fractures in adults were included.

\section{Data collection and analysis}

Two review authors independently performed study selection, risk of bias assessment and data extraction. Authors of the included studies were contacted to obtain original data.

\section{Main results}

Three randomised controlled trials and one quasi-randomised controlled trial were included. These involved a total of 292 participants with ankle fractures. All studies were at high risk of bias from lack of blinding. Additionally, loss to follow-up or inappropriate exclusion of participants put two trials at high risk of attrition bias. The trials used different and incompatible outcome measures for assessing 
function and pain. Only limited meta-analysis was possible for early treatment failure, some adverse events and radiological signs of arthritis.

One trial, following up 92 of 111 randomised participants, found no statistically significant differences between surgery and conservative treatment in patient-reported symptoms (self assessed ankle "troubles": $11 / 43$ versus $14 / 49$; risk ratio (RR) $0.90,95 \%$ CI 0.46 to 1.76 ) or walking difficulties at seven years follow-up. One trial, reporting data for 31 of 43 randomised participants, found a statistically significantly better mean Olerud score in the surgically treated group but no difference between the two groups in pain scores after a mean follow-up of 27 months. A third trial, reporting data for 49 of 96 randomised participants at 3.5 years follow-up, reported no difference between the two groups in a non-validated clinical score.

Early treatment failure, generally reflecting the failure of closed reduction (criteria not reported in two trials) probably or explicitly leading to surgery in patients allocated conservative treatment, was significantly higher in the conservative treatment group (2/116 versus 19/129; RR 0.18, 95\% CI 0.06 to 0.54 ). Otherwise, there were no statistically significant differences between the two groups in any of the reported complications. Pooled results from two trials of participants with radiological signs of osteoarthritis at averages of 3.5 and 7.0 years follow-up showed no between-group differences (44/66 versus 50/75; RR 1.05, 95\% CI 0.83 to 1.31 ).

\section{Authors' conclusions}

There is currently insufficient evidence to conclude whether surgical or conservative treatment produces superior long-term outcomes for ankle fractures in adults. The identification of several ongoing randomised trials means that better evidence to inform this question is likely to be available in future.

\section{PLAIN LANGUAGE SUMMARY}

\section{Surgical versus conservative treatment for ankle fractures in adults}

Each year, one in every 800 people break (fracture) their ankles. Such injuries typically happen to young men and older women. Ankle fractures can be treated surgically or conservatively (non-surgically). Surgery involves an operation to expose the fracture to reposition the broken parts of the bone and then fix them in place using wires, pins, screws and other devices. Treatment after surgery varies but may also include the use of a plaster cast. Conservative treatment involves repositioning of the fractured bone by manipulating it through the skin, followed by immobilisation of the ankle in a plaster cast for several weeks. This review aimed to find out whether surgery or conservative treatment gives a better long-term outcome for people with these injuries.

This review included four trials, involving a total of 292 participants. All four trials had flawed methods that could affect the reliability of their findings. No data could be pooled for long-term measures of function or pain. The largest trial found no evidence of differences between surgery and conservative treatment in patient-reported symptoms or walking difficulties at seven years follow-up. The second trial found better results for the surgical group for function but not pain at 27 months, while the third trial reported no difference between the two groups in clinical outcome at 3.5 years. In all four trials, there were some patients in the conservative treatment group who were treated surgically because the repositioning of the fractured bone was judged unsuccessful. Otherwise, there were no significant differences between the two groups in any of the reported complications nor in radiological signs of osteoarthritis.

Overall, there was not enough reliable evidence to draw conclusions about whether surgery or conservative treatment is more appropriate for treating broken ankles in adults.

B A C K G R O U N D

\section{Description of the condition}

The ankle joint is made up of three bones: the tibia ('shin bone'), the fibula (the other lower-leg bone) and the talus ('ankle bone'). The distal (lower) ends of the tibia and fibula form a 'saddle shaped' joint on top of and around the talus. The specific part of the tibia

Surgical versus conservative interventions for treating ankle fractures in adults (Review) 
that curves down and articulates with the inside facing part of the talus is called the medial malleolus. The posterior malleolus, which is also part of the tibia, is at the back of the ankle joint. The lateral malleolus forms the distal end of the fibula and articulates with the lateral (or outside facing) part of the talus. Situated just above the ankle joint is the 'syndesmosis', which is the joint between the distal tibia and fibula held firmly together by ligaments. Together with the many ankle ligaments, the three malleoli help to keep the ankle joint stable during movement.

A broken ankle or ankle fracture is when one or more parts of the distal tibia or fibula that form the ankle joint are fractured or broken. There will often be associated soft-tissue injuries, particularly to the ankle ligaments. Most ankle fractures are closed injuries, in that the overlying skin remains intact. Around $2 \%$ are open fractures (Court-Brown 1998). An epidemiological study of 1500 ankle fractures in adults attending Edinburgh Royal Infirmary during 1988 to 1991 reported an annual incidence of 122 fractures per 100,000 persons (Court-Brown 1998). Of these, 52\% occurred in men. The age distributions of fractures in men and women differed. The $58 \%$ of fractures that resulted from a simple fall or twisting injury tended to occur in elderly women. Conversely, sports injuries, mainly from soccer accidents, typically occurred in young men.

Court-Brown 1998 reported that the $70 \%$ of fractures were isolated malleolar fractures (predominantly of the lateral malleolus), $23 \%$ were bimalleolar (often of the medial and lateral malleoli) and $7 \%$ were trimalleolar (all three malleoli fractured). As well as categorising ankle fractures by location and the number of malleoli involved, various fracture classification systems have been devised to describe the different fracture patterns and help inform treatment decisions. Three commonly used classification systems for ankle fractures are the Lauge-Hausen system (Lauge Hansen 1942), the Weber system (Weber 1972) and the AO classification system (Müller 1969; Müller 1990). The Lauge-Hansen system classifies injuries by the position of the foot and direction of force at the time of injury (Lauge Hansen 1942). The anatomical classification system of Danis and Weber (Danis 1949; Weber 1972) subgroups fibular fractures as A (below the syndesmosis), B (at the syndesmosis) or $\mathrm{C}$ (above the syndesmosis) depending on the relationship of the fracture to the syndesmosis. The AO classification system is based on fracture patterns alone. Clinical decisions are, however, often made without considerations of these formal classification systems and will take into account also other aspects such as the damage to soft-tissues and the general health of the patient.

\section{Description of the intervention}

Following closed manipulation to achieve reduction of any displaced fractures, conservative management of ankle fractures generally comprises immobilisation in a below-knee cast for several weeks. This is to stabilise the fracture and allow it to heal. Vari- ous methods of immobilisation include casts (plaster or synthetic material), walking casts and functional braces. A Cochrane review on the rehabilitation of ankle fractures includes comparisons of different methods of immobilisation (Lin 2008).

Surgical treatment involves the reduction (if displaced) of the fractured parts and fixation using various devices such as metal plates, screws, tension bands or external fixation. These operative techniques aim to provide anatomical restoration and immediate stability, which facilitates earlier mobilisation. However, all surgery carries the risk of complications such as wound infection, pulmonary embolism, implant or fixation failure, mortality, amputation and reoperation (SooHoo 2009). For an evaluation of postsurgical rehabilitation interventions, see Lin 2008.

\section{How the intervention might work}

Healing of the bone takes at least several weeks and consists of five major phases: induction, inflammation, soft callus formation, ossification and remodelling (Koval 2002). For conservative treatment, immobilisation of the fractured parts is generally considered to be important for bone healing. However, immobilisation can lead to muscle atrophy, cartilage degeneration, and a stiff, painful and swollen joint. Also, conservative treatment can lead to secondary displacement, which generally requires surgery (Dietrich 2002), painful nonunion (Walsh 2004) and prolonged immobilisation.

With early mobilisation and postoperative exercises these adverse effects may be prevented. If surgical treatment can protect or accelerate the bone healing process by securely stabilising the fracture, it can also reduce recovery and 'back-to-work-time' and therefore indirect costs to society. This may not be the case for older people with osteoporosis because the porosity of their bones may increase the risk of fixation failure and thus preclude early mobilisation (Salai 2000a).

Anatomical restoration of displaced fractures is more likely to be achieved using surgical methods. A lateral talar dislocation of only one millimetre results in an average reduction of $42 \%$ of the contact area between talus and tibia (Ramsey 1976), which results in severe peak loads. It is assumed that such peak forces lead to secondary loss of cartilage, which in turn increases the risk of post-traumatic osteoarthritis. The better anatomical stabilisation achieved via surgery might reduce lateral talar dislocation more effectively than immobilisation alone and thus lessen the risk of long-term post-traumatic osteoarthritis. However, as well as the additional risks generally associated with surgery and anaesthesia, patients with conditions such as diabetes and peripheral vascular disease are at increased risk of complications and an unsatisfactory outcome. Moreover, there is evidence that not all fractures need perfect anatomical repair for a satisfactory outcome. Conservative treatment with closed reduction and cast immobilisation can yield good results for certain less severe fracture types (Bauer 1985a; Herscovici 2007; Kristensen 1985). Displaced fractures can be 
treated successfully with closed reduction and plaster cast (Rowley 1986a; Wei 1999). If immobilisation alone gains equal results easily for certain fractures types, surgical interventions should be considered as over-treatment.

\section{Why it is important to do this review}

In current practice, most Weber A fractures are treated conservatively and most Weber $\mathrm{C}$ fractures are treated by open, anatomical reduction and internal fixation. The remainder (roughly 50\%) of all ankle fractures consists of Weber B fractures, which are treated both surgically and conservatively. Some clinicians think conservative measures are adequate in ankle fractures, but others consider exact anatomical reconstruction is essential to prevent predisposition for post-traumatic osteoarthritis. The rate of surgical interventions increases with the number of malleoli fractured, but depending on location, a wide range ( $14 \%$ to $72 \%)$ in the rate of surgical interventions has been reported in the USA (Koval 2005). There is also controversy in the treatment of older people with osteoporotic bones and other comorbidities that increase the risk of surgical complications (SooHoo 2009). Additionally, the LaugeHansen and Weber classification systems are not able to assess the intrinsic stability of all ankle fractures, which is considered an important determinant for the type of treatment. To compare the outcome of both treatment modalities for ankle fractures in adults, a systematic evaluation of benefits and harms is needed.

\section{Types of participants}

Studies including adult participants with ankle fractures who underwent a surgical or conservative intervention were included. Trials containing adults and children were included if the proportion of children was clearly small $(<5 \%)$, or if separate data for adults could be obtained. Similarly, we excluded studies in which participants with more extensive fractures of the distal third of the tibia (pilon or tibial plafond fractures) or studies that included more than $5 \%$ fractures with delayed presentation, unless separate data for acute ankle fractures could be obtained. Studies evaluating surgical revision of displaced fractures were excluded.

\section{Types of interventions}

Studies comparing any type of surgical treatment with any type of conservative intervention were included. The following procedures were compared:

- Any kind of fracture stabilisation with osteosynthesis (lag screw, plates, tension bands, bridge plating, external fixation or internal fixation)

versus

- Any kind of fracture stabilisation with non-invasive interventions (plaster cast immobilisation, walking cast, orthosis, any kind of removable type of immobilisation).

\section{Types of outcome measures}

\section{Primary outcomes}

The primary outcome measures were functional outcome, pain and major adverse events. Preference was given to validated outcome measures, including visual analogue scale readings for pain. Examples of validated outcome measures included the physiciancompleted Olerud Molander Ankle Score (Olerud 1984), patientrated functional outcomes such as the Lower Extremity Function Scale (Binkley 1999), and appropriate components of generic quality of life measures (e.g. SF36, SF12, and EQ-5D).

Major adverse events were generally considered as those related to the fracture or intervention that required secondary intervention (i.e. the need for surgery or further surgery; or prolonged intensive rehabilitation). Adverse events included insufficient primary osteosynthesis, soft tissue necrosis and any infection, osteitis, post-traumatic thrombosis, delayed union, nonunion, secondary fracture displacement, re-fracture, joint stiffness, muscular atrophy, tendinous insufficiency, sensory deficit, tarsal tunnel syndrome, and complex regional pain syndrome type 1 (also known as Sudeck's dystrophy or reflex sympathetic dystrophy) (Stanton-Hicks 1995). 


\section{Secondary outcomes}

The secondary outcome measures sought included measures of recovery such as time to resume normal activities or return to work, range of motion, measures of functional impairment, anatomical result (x-ray) and radiologically-defined osteoarthritis.

\section{Search methods for identification of studies}

\section{Electronic searches}

The search was conducted in two stages. We initially searched the Cochrane Bone, Joint and Muscle Trauma Group Specialised Register (to 4 June 2010), the Cochrane Central Register of Controlled Trials (The Cochrane Library, 2010 Issue 2), MEDLINE (PubMed,1965 to 4 June 2010), EMBASE (Elsevier, 1974 to 4 June 2010) and CINAHL (EBSCO, 1981 to 4 June 2010). We also searched the WHO International Clinical Trials Registry Platform (to 4 June 2010) and Current Controlled Trials (to 4 June 2010) for ongoing or recently completed trials. We then updated our search up to 6 February 2012, setting the initial date of search from 1 January 2010, for the following: the Cochrane Bone, Joint and Muscle Trauma Group Specialised Register, the Cochrane Central Register of Controlled Trials (The Cochrane Library, 2012 Issue 1), MEDLINE, EMBASE (searched using the Ovid interface), CINAHL and the WHO International Clinical Trials Registry Platform and Current Controlled Trials.

The MEDLINE strategy was developed in accordance with the guidelines outlined in the Cochrane Handbook for Systematic Reviews of Interventions (Lefebvre 2009a). The subject-specific search was combined with the Cochrane Highly Sensitive Search Strategy for identifying randomised trials in MEDLINE: sensitivity- and precision-maximising version (Lefebvre 2009b). This strategy was adapted to the syntax and capacities of the other databases (see Appendix 1). There were no restrictions based on language.

\section{Searching other resources}

We looked for additional relevant trials by checking the reference lists of identified randomised trials. All authors of included trials were asked for additional information on any published, unpublished, or ongoing trials.

\section{Data collection and analysis}

\section{Selection of studies}

The titles, abstracts and descriptor terms of all downloaded material from the electronic searches were read by CD, who discarded clearly irrelevant reports. The remaining citations were then screened independently by CD and HA to establish the need for obtaining full articles. Full articles were also obtained where there was any uncertainty about the relevance of the study. Subsequently, $\mathrm{CD}$ and HA independently applied the inclusion criteria. Any differences in study inclusion were resolved by discussion with a third review author $(\mathrm{CL})$.

\section{Data extraction and management}

Two review authors (CD and HA) independently extracted the data using a pre-piloted data extraction form. Any disagreement was resolved by discussion, if necessary approaching a third author. Where necessary, trial authors were contacted for further information on their trials. Extracted data were stored and managed using Review Manager. If required, interim statistical calculations were performed by CD and CL.

\section{Assessment of risk of bias in included studies}

Two review authors (CD and HA) independently assessed the risk of bias of each included study. Any differences were resolved by discussion, with arbitration by a third review author (CL). We used The Cochrane Collaboration's 'Risk of bias' tool (Higgins 2008). Each study was graded for risk of bias in each of the following domains: sequence generation, allocation concealment, blinding, incomplete outcome data, selective outcome reporting and 'other' (for instance, extreme baseline imbalance). We also assessed performance bias, specifically in terms of surgeon's experience.

\section{Measures of treatment effect}

Treatment effect was measured using risk ratios for binary data, and mean differences or, where different outcome measures were used, standardised mean differences for continuous data. Ninetyfive percent confidence intervals were used throughout.

\section{Unit of analysis issues}

As expected, the unit of randomisation was the individual patient in the included trials. There were no trials with a clusterrandomised design.

\section{Dealing with missing data}

Trial investigators were contacted for additional data if necessary. Where appropriate, we performed intention-to-treat analyses to include all people randomised to the intervention groups. We investigated the effect of drop-outs and exclusions by conducting sensitivity analyses. We were also alert to the potential mislabelling or non identification of standard errors and standard deviations. In case of missing data, we investigated whether they were missing at random, in which case the missing data was to be regarded as not having an important influence on outcome, or missing not 
at random. If data were deemed to be missing not at random, we stated that replacement values would not be imputed but sensitivity analyses would be considered.

\section{Assessment of heterogeneity}

We judged the appropriateness of pooling by assessing clinical diversity in terms of participants, interventions and outcomes of the included studies. Statistical heterogeneity was assessed by visual inspection of the forest plot and by using the $\mathrm{I}^{2}$ and $\mathrm{Chi}^{2}$ statistical tests.

\section{Assessment of reporting biases}

Had sufficient data for the primary outcomes been available, we planned to assess publication bias using funnel plots.

\section{Data synthesis}

Where judged appropriate, we planned to pool data using both the fixed-effect (DeMets 1987) and random-effects models (DerSimonian 1986). Where there was no important difference between the two results, the results from the fixed-effect model were presented. Otherwise, depending on the results of heterogeneity tests, results from both models would have been presented.

\section{Subgroup analysis and investigation of heterogeneity}

If sufficient pooled data were available, we intended to conduct subgroup analyses to compare the effects of the interventions according to the risk of bias of the trials (low risk versus unclear or high risk), type of fracture (Weber A, B and C; displaced versus non-displaced), age (under 65 years; 65 or over), comorbidity (diabetic; non-diabetic), surgical experience (resident versus surgeon), different definitions of union (clinical versus radiological), and types of surgical (plate versus other fixation) or conservative treatment (e.g. early mobilisation versus immobilisation).

\section{Sensitivity analysis}

We intended to perform sensitivity analysis of pooled data examining various aspects of trial and review methodology, including the effects of missing data, and the inclusion of trials at high risk of bias (primarily, lack of allocation concealment) and trials only reported in abstracts.

\section{RES U L T S}

\section{Description of studies}

See: Characteristics of included studies; Characteristics of excluded studies; Characteristics of ongoing studies.

See: Characteristics of included studies; Characteristics of excluded studies; Characteristics of ongoing studies.

\section{Results of the search}

After performing the first search up to 4 June 2010 (see Appendix 1) and removing duplicates, 1352 titles and abstracts were reviewed. Our subsequent search (2010 to 6 February 2012) resulted in 399 reference citations after the removal of duplicates (MEDLINE (48); The Cochrane Library (16); EMBASE (262); CINAHL (115)). Overall, of 18 potentially eligible studies, four were included, nine were excluded and five are ongoing or yet to be published trials (as of February 2012). All contact authors of the included trials (and the contact author of Salai 2000) were approached for additional information and clarification. While we were successful in contacting the authors of Phillips 1985 and Salai 2000 , neither was able to provide additional information.

\section{Included studies}

The four included studies (Bauer 1985; Makwana 2001; Phillips 1985; Rowley 1986) involved a total of 292 participants. These are summarised below, with a full summary for each trial detailed in the Characteristics of included studies.

\section{Design}

Three included trials (Bauer 1985; Makwana 2001; Phillips 1985) were randomised controlled trials and one trial (Rowley 1986) was a quasi-randomised controlled trial.

\section{Sample sizes}

The study population sizes at randomisation varied: 42 patients (Rowley 1986), 43 patients (Makwana 2001), 96 patients (Phillips 1985) and 111 patients (Bauer 1985).

\section{Setting}

All four trials were hospital based. Bauer 1985 was conducted in two hospitals in Sweden. The other three were single centre trials carried out in the UK (Makwana 2001; Rowley 1986) and the US (Phillips 1985). The first year of patient recruitment spanned from 1968 in Bauer 1985 to 1995 in Makwana 2001.

\section{Participants}

Information on gender was available for three trials: Bauer 1985 (64 female, 44 male); Makwana 2001 (31 female, 12 male); and Phillips 1985 (54 female, 42 male). In all, participant age varied between 15 and 91 years but Makwana 2001 set a lower age limit 
of 55 years and thus recruited an older population than the other three trials.

Bauer 1985 included patients with a displaced type A or B malleolar fracture. Makwana 2001 included patients with a displaced ankle fracture. Phillips 1985 evaluated patients with a closed supination-external rotation grade- 4 or a pronation-external rotation grade- 4 ankle fracture, classified according to the modified Lauge Hansen system (Lauge Hansen 1942), for whom a satisfactory closed reduction had been achieved. Rowley 1986 included patients with a displaced ankle fracture. Closed reduction was performed in all four trials.

\section{Interventions}

Essentially, all four trials compared open reduction and internal fixation (ORIF) versus closed reduction and plaster cast immobilisation (conservative treatment).

In Bauer 1985, Makwana 2001 and Rowley 1986, surgical treatment was in accordance with AO/ASIF principles (Müller 1979). Phillips 1985 described the use of surgical techniques based on those of the Association for the Study of Internal Fixation (ASIF) (not referenced).

Bauer 1985 compared ORIF (followed by bed rest for five days, partial weight bearing from six weeks and full weight bearing at nine weeks) versus closed reduction and a plaster cast for six weeks (followed by partial weight bearing from six weeks and full weight bearing at nine weeks).

Makwana 2001 compared ORIF followed by a below-knee plaster cast for six weeks with protected weight bearing versus closed reduction followed by a below-knee plaster cast for six weeks with protected weight bearing.

In Phillips 1985, all participants had had a satisfactory closed reduction before randomisation to ORIF (followed by a belowknee plaster cast for one week; walking on crutches without weight bearing started a few days after surgery until the tenth week) versus a long-leg plaster cast for six weeks without weight-bearing and a below-knee for a further four weeks.

Rowley 1986 compared ORIF (followed by a below-knee backslab and active ankle movement for up to five days, then plaster cast for six weeks) versus closed reduction and a long-leg plaster cast for six weeks. Early weight bearing was encouraged in both groups.
The criteria for successful closed reduction were not clearly/precisely defined in Bauer 1985 and Rowley 1986. Both Makwana 2001 and Phillips 1985 used the same set of five criteria to define a satisfactory closed reduction.

\section{Outcomes}

Length of follow-up duration varied between 20 weeks (Rowley 1986) and an average of seven years (Bauer 1985). All four trials used different approaches to measuring function and clinical outcome. Bauer 1985 and Phillips 1985 used non-validated tools, whereas Makwana 2001 used the Olerud and Molander ankle score (Olerud 1984) as well as a visual analogue score to assess pain. The composite scoring scheme devised by Phillips 1985 assessed clinical and anatomical outcomes and arthritis. Rowley 1986 reported on the presence of foot deformity and foot print analysis for detecting abnormal foot angles. All four trials reported on complications and, to various extents, radiological outcomes.

\section{Excluded studies}

There were nine excluded studies. Strömsöe 1995 did not compare surgical versus conservative treatment. The other eight studies compared surgical versus conservative treatment in ankle fractures, but were excluded because they were not randomised controlled trials (see the Characteristics of excluded studies). In particular, the claim to be a randomised trial in the report of Salai 2000 was not substantiated either through contact with the trial author or by the inappropriate presentation of study results.

\section{Ongoing studies}

We identified five ongoing trials (Gray; Harris; Pakarinen; Sanders; Willett), details of which can be found in the Characteristics of ongoing studies. Three trials are multi-centre studies. Two studies will be finished in 2014 and 2016. The publication of three studies was delayed; although they were due to finish in 2010, no published results were identified by our search in February 2012.

\section{Risk of bias in included studies}

See: Risk of bias in included studies; Figure 1; Figure 2. 
Figure I. Risk of bias summary: review authors' judgements about each risk of bias item for each included study.

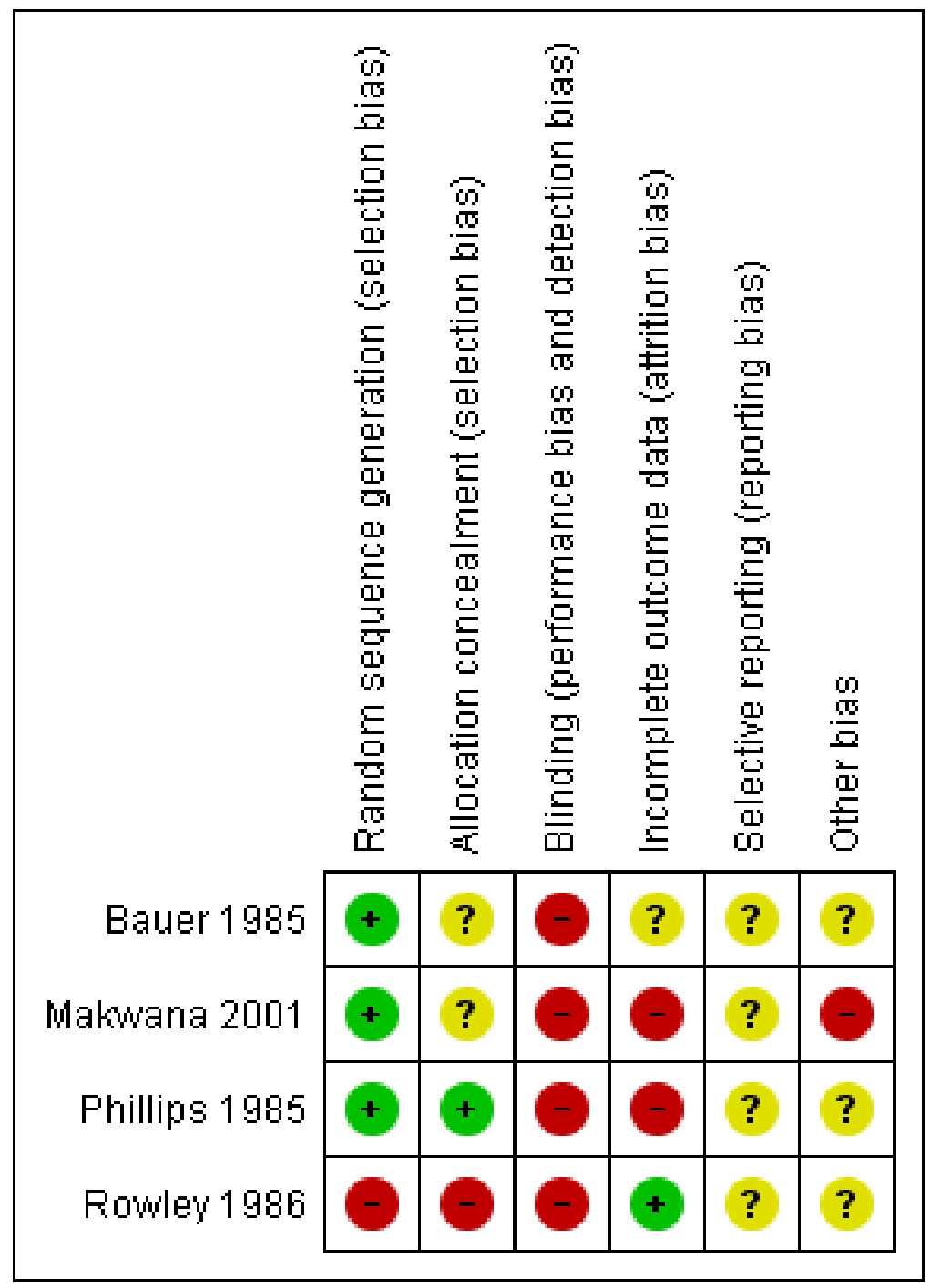


Figure 2. Risk of bias graph: review authors' judgements about each risk of bias item presented as percentages across all included studies.

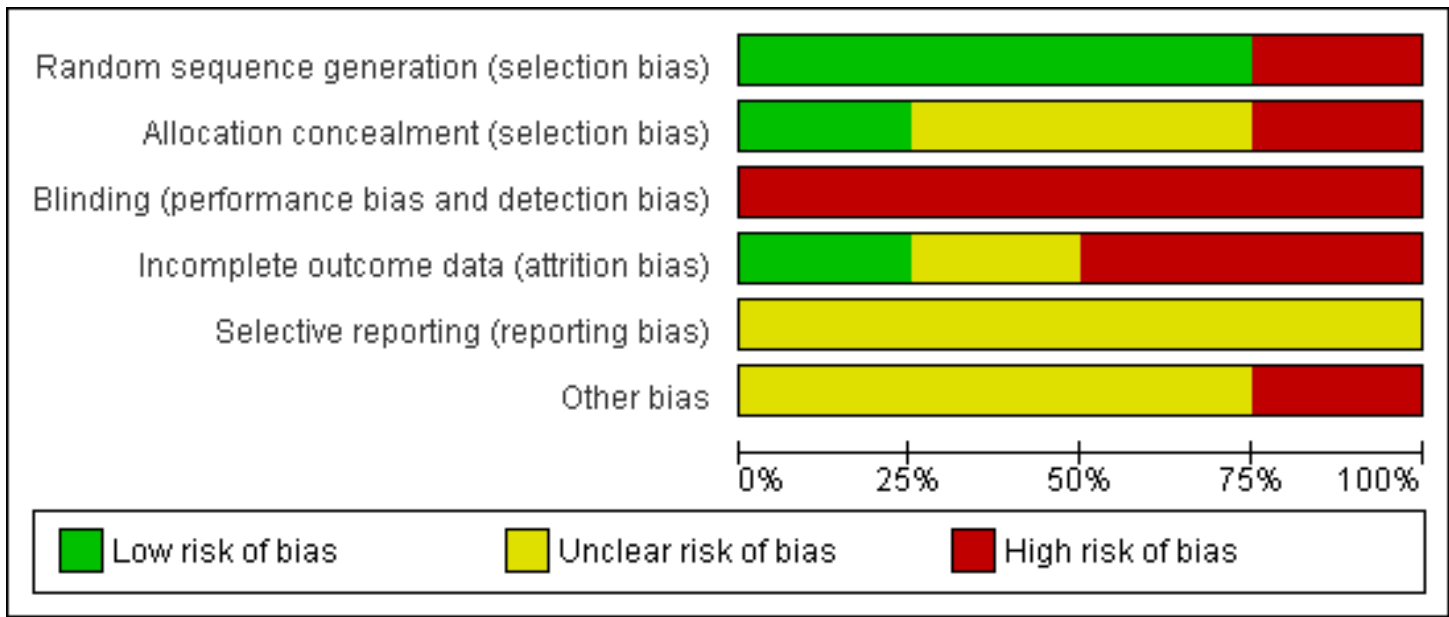

Due to the high level of missing data, all authors were approached for additional information. Only one attempt was successful ( Phillips 1985), but no additional information was obtained.

\section{Allocation}

Generation of the allocation sequence was considered of low risk of bias in three trials (Bauer 1985; Makwana 2001; Phillips 1985) and high risk in Rowley 1986, the allocation of which was based on the patient's record number. Allocation concealment was judged at low risk of bias in Phillips 1985, at high risk in Rowley 1986, and of unclear risk in the remaining two trials (Bauer 1985; Makwana 2001) which provided no details of this aspect.

\section{Blinding}

We acknowledge blinding can be difficult due to the nature of the intervention, but nevertheless none of the studies provided information about blinding and thus all were judged at being at high risk of both performance and detection bias.

\section{Incomplete outcome data}

The risk of attrition bias was considered high in Phillips 1985 (large (49\%) loss of follow-up) and Makwana 2001 (exclusion of eight conservatively treated patients with secondary dislocation; lack of intention-to-treat analysis). Bauer 1985 was judged at unclear risk of bias: while intention-to-treat-analysis was performed and few were lost to follow-up, the effect of the exclusion of type A fractures at follow-up is unknown. In Rowley 1986, two patients were excluded from the analysis because they required secondary surgery after failed manipulation. The authors' intention was to analyse these patients separately but this was not done and intention-to-treat analysis was not performed. However, this was unlikely to alter the findings of the trial, which was thus judged to be at low risk of attrition bias.

\section{Selective reporting}

As we did not have access to the study protocols, we judged this to be at unclear (unknown) risk of bias.

\section{Other potential sources of bias}

In Makwana 2001, the imbalance in the number of smokers $(0$ versus 6) between the two groups was considered to be another potential source of bias. No information was available to assess potential other sources of bias in any of the included studies.

\section{Effects of interventions}

All authors were contacted to obtain the original data, but none was forthcoming. The lack of these data prevented our plans to study the outcomes in different subgroups.

\section{Primary outcomes}

Based on the results of a non-validated questionnaire, Bauer 1985 found no difference between the two groups at seven years in the incidence of people with self-assessed significant 'troubles' from their ankle (11/43 versus 14/49; risk ratio (RR) 0.90, 95\% CI 0.46 to 1.76 ; see Analysis 1.1). With the exception of a marginally statistically significant difference in favour of the conservative treatment group in the numbers of participants reporting swelling, 
there were no statistically significant differences between the two groups in participants reporting problems of pain, restricted range of motion, unsteadiness and 'passing stiffness' (see Analysis 1.1). There were also no statistically significant differences between the two groups in walking difficulties on rough or even ground (see Analysis 1.1). Four participants, two from each group, formerly employed as heavy manual labourers, changed occupation or quit working because of their ankle fracture. Makwana 2001 found a significantly better mean Olerud score (Olerud 1984) in the surgically treated group after a mean follow-up of 27 months (mean difference (MD) 17.00, 95\% CI 0.64 to 33.36; see Analysis 1.2). At 3.5 years of follow-up, Phillips 1985 found a significant difference in favour of the surgical group for a non-validated combined score ( 0 to 150 : best outcome) that rated clinical, anatomical and arthritis outcome (MD 10.30, 95\% CI 0.93 to 19.67; see Analysis $1.2)$; however, there was no difference between the two groups in the clinical scores (subjective + objective assessment: 100 possible points): 88.8 versus 84.3 , difference reported as non significant. Makwana 2001 found no difference in pain scores at 27 months (see Analysis 1.3).

While Bauer 1985 and Phillips 1985 retained for the purposes of intention-to-treat analyses those patients who did not receive their allocated intervention or were otherwise early treatment failures (i.e. failure of closed reduction), the other two trials explicitly excluded these. There were significantly more early treatment failures in the conservative treatment group (2/116 versus 19/129; RR $0.18,95 \%$ CI 0.06 to 0.54 ; see Analysis 1.4 ). Skin damage precluded operations for two participants allocated surgery in Bauer 1985. As shown in the rest of the analyses in Analysis 1.4, there were no significant differences between the two groups in any of the specified complications (deep infection, superficial infection, surgical wound closure problem, skin ulcer, deep vein thrombosis, complex regional pain syndrome type 1 (Stanton-Hicks 1995), need for removal of internal fixation, surgical scar tenderness). It is noteworthy that all four conservative treatment group patients with wound infections in Bauer 1985 were patients who received surgery after closed treatment had failed.

\section{Secondary outcomes}

Bauer 1985 showed no differences between the surgical and conservative groups in range of motion parameters at seven years (see Analysis 1.6). In Makwana 2001, the loss of dorsal range of motion compared with the contralateral ankle at follow-up was significantly less in the surgically treated group ( 9 versus 16 degrees, reported $\mathrm{P}=0.044)$. Rowley 1986 found no statistically significant differences between the two groups regarding restriction of dorsiflexion or abnormal foot angle at 20 weeks follow-up (see Analysis 1.5). Time to independent weight bearing by all patients in Rowley 1986 was 16 weeks for the surgical group and 12 weeks for the conservative group.

At 3.5 years of follow-up, Phillips 1985 found a significant dif- ference in favour of the surgical group in the anatomical scores (26.7 versus 22.1 (out of a maximum score of 35); reported $\mathrm{P}$ $<0.05$ ). Pooled results for participants with radiological signs of osteoarthritis from two trials (Bauer 1985; Phillips 1985) showed no between-group differences (44/66 versus 50/75; RR 1.05, 95\% CI 0.83 to 1.31 ; see Analysis 1.8).

In Bauer 1985, patients receiving surgical treatment left the hospital significantly later than conservatively treated patients (mean 9.5 versus 5.0 days, reported $\mathrm{P}<0.05)$; 17 (30\%) participants of the conservative treatment group were treated as outpatients. The median time of sick leave of fully employed participants was 14 weeks in both groups of Bauer 1985. In Makwana 2001, patients receiving surgery also left the hospital significantly later than the conservatively treated patients (mean 6.7 versus 2.6 days, mean difference 4.10 days, 95\% CI 2.62 to 5.58; see Analysis 1.9).

\section{DISCUSSION}

\section{Summary of main results}

Four controlled trials (three randomised and one quasi-randomised) involving a total of 292 adults with displaced ankle fractures were included in this review.

Meta-analyses for functional outcome and pain were impossible due to the incompatible outcome measures used by the trials. The largest trial (Bauer 1985), following up 92 of 111 randomised participants, found no statistically significant differences between surgery and conservative treatment in the number of patients reporting symptoms and walking difficulties at seven years followup. One trial (Makwana 2001), reporting data for 31 of 43 randomised participants, found a significantly better mean Olerud score in the surgically treated group but no difference between the two groups in pain scores after a mean follow-up of 27 months. A third trial (Phillips 1985), reporting data for 49 of 96 randomised participants at 3.5 years follow-up, reported no difference between the two groups in a non-validated clinical score.

Early treatment failure, generally reflecting the failure of closed reduction (criteria not reported in two trials) probably or explicitly leading to surgery in patients allocated conservative treatment, was significantly higher in the conservative treatment group. Such patients were incorrectly excluded from the analyses of two trials. Otherwise, there were no significant differences between the two groups in any of the reported complications.

Bauer 1985 found no differences between the surgical and conservative groups in range of motion at seven years, whereas Makwana 2001 reported a better range of motion result for the surgically treated group. One trial (Rowley 1986) reporting data for 40 participants at 20 weeks follow-up found no statistically significant differences between the two groups regarding restriction of dorsiflexion or abnormal foot angle. Phillips 1985 found better anatom- 
ical scores in the surgical group at 3.5 years of follow-up. Pooled results for participants with radiological signs of osteoarthritis from two trials showed no between-group differences.

Two trials found that patients receiving surgical treatment stayed in hospital on average four days longer than conservatively treated patients.

\section{Overall completeness and applicability of evidence}

This review contains only four trials with a total of 292 participants. However, functional outcome data were available for far fewer participants (170 patients in three trials) and, moreover, these could not be pooled.

There were important differences between the four trials, including the types of participants (e.g. Makwana 2001 only recruited people over 55 years old), the surgical techniques (e.g. in Bauer 1985, ligamentous injuries were sutured, whereas this was not done in Makwana 2001), conservative treatment (e.g. types and duration of plaster cast immobilisation), the post-surgical treatment regimens (type and duration of plaster cast, early weightbearing or not, early active movements or not), and in the duration of follow-up and assessment of outcome. This variation, as well as lack of information on these trial characteristics (including the criteria for a satisfactory closed reduction), hinder the assessment of the applicability of the already limited and flawed evidence. Duration of follow-up in Rowley 1986 of just 20 weeks is clearly unsatisfactory for a full assessment of outcome but it is also noteworthy that even a follow-up of seven years as in Bauer 1985 is insufficient to ascertain post-traumatic osteoarthritis. Horisberger 2009 showed that the latency time to end stage osteoarthritis after an ankle fracture can be as much as 20 years.

\section{Quality of the evidence}

Overall, the quality of the evidence is very limited. We judged the risk of bias was unclear or high in the majority of categories for the four trials. Rowley 1986 was quasi-randomised and thus at high risk of selection bias and all trials were at risk of bias due to lack of blinding, including of assessors. Of note is the high risk of attrition bias from incomplete outcome data in Makwana 2001, which incorrectly excluded patients after randomisation, and Phillips 1985, which had a large loss to follow-up. All trials were small and insufficient to confirm any lack of differences between the two groups.

\section{Potential biases in the review process}

The review was performed according to the unchanged published protocol. We tried to minimise publication bias by undertaking a comprehensive search strategy and checking non-English language citations (a translation of a Polish and German study resulted in their exclusion). Our search also included a search for ongoing and recently completed trials. However, it is still possible that potentially relevant trials have been missed. Additionally, although unsuccessful, we tried to obtain additional data and information from the included trialists.

\section{Agreements and disagreements with other studies or reviews}

The conclusion of this review is in line with another systematic review about the surgical versus conservative treatment of ankle fractures (Petrisor 2006). Petrisor 2006 also included Salai 2000, which we excluded because it did not appear to be randomised (and its data were unusable). Our search also located five ongoing or unpublished trials that may be included in a future update of this review.

\section{A U THORS' CONCLUSIONS}

\section{Implications for practice}

There is insufficient evidence to conclude whether surgical or conservative treatment produces superior long-term outcomes for ankle fractures in adults.

\section{Implications for research}

In future, adequately powered well designed and conducted, and appropriately reported clinical trials could provide more robust data. They should use validated outcome measures. Ideally, patients should be followed up for several years after randomisation and standard treatment regimens for surgical or conservative interventions should be used. Inclusion criteria and randomisation should take into account fracture type and displacement. However, before embarking on any new trials, it is important to note the existence of several ongoing studies, including a large multicentre trial aiming to recruit over 600 patients. These trials also point to the importance of updating this review in due course.

\section{ACKNOWLEDGEMENTS}

The authors would like to thank Kate Bugler, William Gillespie, Helen Handoll and Caroline Hing for their valuable comments on drafts of the protocol and review. We also acknowledge the help of Lindsey Elstub, Joanne Elliott and Amy Kavanagh. 


\section{R E F E R E N C E S}

\section{References to studies included in this review}

Bauer 1985 \{published data only\}

Bauer M, Bergstrom B, Hemborg A, Sandegard J. Closed versus open treatment of Weber type B ankle fracture [abstract]. Acta Orthopaedica Scandinavica 1986;57:607.

* Bauer M, Bergström B, Hemborg A, Sandegärd J. Malleolar fractures: nonoperative versus operative treatment. A controlled study. Clinical Orthopaedics and Related Research 1985;(199):17-27. [PUBMED: 3930121] Bauer M, Johnell O, Redlund-Johnell I, Johnsson K. Ankle fractures. Foot and Ankle 1987;8:23-5.

Makwana 2001 \{published data only\}

Makwana N, Bhowal B, Harper A. Displaced ankle fractures in the over 55 years of age. A prospective randomised study [abstract]. Journal of Bone and Joint Surgery - British Volume 1999;81 Suppl 2:160.

* Makwana NK, Bhowal B, Harper WM, Hui AW. Conservative versus operative treatment for displaced ankle fractures in patients over 55 years of age. A prospective, randomised study. Journal of Bone and Joint Surgery - British Volume 2001;83(1):525-9. [PUBMED: 11380123] Ramasamy PR, McDermott ID, Fowler AW, Makwana NK, Bhowal B, Harper WM. Conservative versus operative treatment for displaced ankle fractures in patients over 55 years of age (letters). Journal of Bone and Joint Surgery British Volume 2001;83(7):1084-6.

Phillips 1985 \{published data only\}

Harper MC, Phillips WA. A prospective, randomized study of the management of severe ankle fractures [letters]. Journal of Bone and Joint Surgery - American Volume 1985; 67:1303-4.

* Phillips WA, Schwartz HS, Keller CS, Woodward HR, Rudd WS, Spiegel PG, Laros GS. A prospective, randomized study of the management of severe ankle fractures. Journal of Bone and Joint Surgery - American Volume 1985;67:67-78. [PUBMED: 3881447]

Rowley 1986 \{published data only\}

Rowley DI, Norris SH, Duckworth T. A prospective trial comparing operative and manipulative treatment of ankle fractures. Journal of Bone and Joint Surgery - British Volume 1986;68:610-3. [PUBMED: 3090049]

\section{References to studies excluded from this review}

Dietrich 2002 \{published data only\}

Dietrich A, Lill H, Engel T, Schönfelder M, Josten C. Conservative functional treatment of ankle fractures. Archives of Orthopaedic Trauma Surgery 2002;122:165-8.

Doleż al 1995 \{published data only\}

Doleż al SA. Assessment of therapeutic results of lateral ankle fractures [Ocena wyników leczenia zł amań

kostki bocznej]. Wiadomoś ci Lekarskie 1995;48:5-9. [CENTRAL: CN-00151986]
Hughes 1979 \{published data only\}

Hughes JL, Weber H, Willenegger H, Kuner EH.

Evaluation of ankle fractures: non-operative and operative treatment. Clincal Orthopaedics and Related Research 1979; 138:111-9. [PUBMED: 445892]

Richter 1994 \{published data only\}

Richter J, Josten C, Schildhauer T, Muhr G. Conservative versus operative treatment for Weber B fractures [Funktionell-konservative versus operative therapie der Weber-B-fraktur]. Langenbecks Arch Chir Suppl 1994;Suppl Kongressbericht:923-6. [CENTRAL: $\mathrm{CN}-00396173$ ]

Salai 2000 \{published data only\}

* Salai M, Dudkieweicz I, Novikov I, Amit Y, Chechick A. The epidemic of ankle fractures in the elderly - is surgical treatment warranted?. Archives of Orthopaedic Trauma Surgery 2000;120:511-3. [PUBMED: 11011670] Salai M, Dudkiewitz I, Novikov I, Amit Y, Chechick A. Ankle fractures in the elderly-is surgical treatment warranted? [abstract]. Journal of Bone and Joint Surgery British Volume 1999;81 Suppl 2:160-1.

Strömsöe 1995 \{published data only\} Strömsöe K, Höqevold HE, Skjeldal S, Alho A. The repair of a ruptured deltoid ligament is not necessary in ankle fractures. Journal of Bone and Joint Surgery - British Volume 1995;77-B:920-1. [PUBMED: 7593106]

Velkovski 1995 \{published data only\}

Velkovski G. The value of osteosynthesis in the treatment of bimalleolar fractures. Annales Chirurgiae et Gynaecologiae 1995;84:403-16. [PUBMED: 8687088]

Yde 1980a \{published data only\}

Yde J, Kristensen D. Ankle fractures. Supination-eversion stage II; primary and late results of operative and nonoperative treatment. Acta Orthopaedica Scandinavica 1980; 51:695-702. [PUBMED: 6778066]

Yde 1980b \{published data only\}

Yde J, Kristensen D. Ankle fractures. Supination-eversion stage IV; primary and late results of operative and nonoperative treatment. Acta Orthopaedica Scandinavica 1980; 51:981-90.

\section{References to ongoing studies}

Gray \{published data only\}

Gray B. Influence of ankle skin perfusion on fracture treatment outcomes in the elderly: a randomised controlled trial comparing total contact cast with open reduction and internal fixation, the effect on cutaneous blood supply and relationship to skin complications. http://www.controlledtrials.com/ISRCTN81174170 (accessed 6 February 2012).

Harris \{published data only\}

Harris I, Mittal R. Combined randomised and observational study of type B ankle fracture treatment (CROSSBAT). http://clinicaltrials.gov/ct2/show/NCT01134094 (accessed 6 February 2012). 
Pakarinen \{published data only\}

Pakarinen H. Syndesmotic Injury and Fixation in Supination-External (SE) Ankle Fractures. http:// clinicaltrials.gov/ct2/show/NCT01234493 (accessed 6 February 2012).

\section{Sanders \{published data only\}}

Sanders D. Operative versus non operative treatment for unstable ankle fractures. http://clinicaltrials.gov/ct2/show/ NCT00336752 (accessed 6 February 2012).

\section{Willett \{published data only\}}

* Willett K. Comparison of close contact cast (CCC) technique to open surgical reduction and internal fixation (ORIF) in the treatment of unstable ankle fractures in patients over 60 years. http://www.controlled-trials.com/ ISRCTN04180738 (accessed 6 February 2012). Willett K. Comparison of close contact cast (CCC) technique to open surgical reduction and internal fixation (ORIF) in the treatment of unstable ankle fractures in patients over 60 years. NIHR Health Technology Assessment Programme. HTA research projects: http:// www.hta.ac.uk/1781 (accessed 2 February 2012).

\section{Additional references}

\section{Bauer 1985a}

Bauer M, Bergström B, Hemborg A, Sandegärd J. Malleolar fractures: nonoperative versus operative treatment. A controlled study. Clinical Orthopaedics and Related Research 1985;(199):17-27. [PUBMED: 3930121]

\section{Binkley 1999}

Binkley JM, Stratford PW, Lott SA, Riddle DL. The Lower Extremity Functional Scale (LEFS): scale development, measurement properties, and clinical application. North American Orthopaedic Rehabilitation Research Network. Physical Therapy 1999;79(4):371-83. [PUBMED: 10201543]

\section{Cedell 1967}

Cedell CA. Supination-outward rotation injuries of the ankle. Acta Orthopaedica Scandinavica 1967;suppl 110: 1-117. [PUBMED: 4970319]

\section{Court-Brown 1998}

Court-Brown CM, McBirnie J, Wilson G. Adult ankle fractures - an increasing problem?. Acta Orthopaedica Scandinavica 1998;69(1):43-7. [PUBMED: 9524517]

\section{Danis 1949}

Danis R. Malleolar fractures [Les fractures malléolaires]. Théorie et pratique de l'ostéosynthèse, Liège: Desoer et Masson 1949;I: $133-65$.

\section{DeMets 1987}

DeMets DL. Methods of combining randomized clinical trials: strengths and limitations. Statistics in Medicine 1987; 6(3):341-50. [PUBMED: 3616287]

\section{DerSimonian 1986}

DerSimonian R, Laird N. Meta-analysis in clinical trials. Controlled Clinical Trials 1986;7(3):177-88. [PUBMED: 3802833]

\section{Herscovici 2007}

Herscovici D Jr, Scaduto JM, Infante A. Conservative treatment of isolated fractures of the medial malleolus. Journal of Bone \& Joint Surgery - British Volume 2007;89(1): 89-93. [PUBMED: 17259423]

Higgins 2008

Higgins JPT, Green S (editors). Cochrane Handbook for Systematic Reviews of Interventions Version 5.0.1 [updated September 2008]. The Cochrane Collaboration 2008. Available from www.cochrane-handbook.org.

Horisberger 2009

Horisberger M, Valderrabano V, Hintermann B. Posttraumatic ankle osteoarthritis after ankle-related fractures. Journal of Orthpaedic Trauma 2009;23(1):60-7. [PUBMED: 19104305]

Koval 2002

Koval, KJ. Orthopaedic Knowledge Update 7: Home Study Syllabus. 1st Edition. New York: American Academy of Orthopaedic Surgeons, 2002.

Koval 2005

Koval KJ, Lurie J, Zhou W, Sparks MB, Cantu RV, Sporer SM, et al.Ankle fractures in the elderly: what you get depends on where you live and who you see. Journal of Orthopaedic Trauma 2005;19(9):635-9. [PUBMED: 16247309]

\section{Kristensen 1985}

Kristensen KD, Hansen T. Closed treatment of ankle fractures. Stage II supination-eversion fractures followed for 20 years. Acta Orthopaedica Scandinavica 1985;56(2): 107-9. [PUBMED: 3925710 ]

\section{Lauge Hansen 1942}

Lauge Hansen N. Anklebrud I. Genetisk diagnose og reposition [Dissertation]. Munksgaard, Copenhagen, 1942.

\section{Lefebvre 2009a}

Lefebvre C, Manheimer E, Glanville J. Chapter 6: Searching for studies. In: Higgins JPT, Green S (editors). Cochrane Handbook for Systematic Reviews of Interventions Version 5.0.2 (updated September 2009). The Cochrane Collaboration, 2009. Available from www.cochranehandbook.org.

\section{Lefebvre 2009b}

Lefebvre C, Manheimer E, Glanville J. Chapter 6.4.11: Search filters. In: Higgins JPT, Green $S$ (editors). Cochrane Handbook for Systematic Reviews of Interventions Version 5.0.1 (updated September 2009). The Cochrane Collaboration, 2009. Available from www.cochranehandbook.org.

\section{Lin 2008}

Lin CWC, Moseley AM, Refshauge KM. Rehabilitation for ankle fractures in adults. Cochrane Database of Systematic Reviews 2008, Issue 3. [DOI: 10.1002/ 14651858.CD005595.pub2]

\section{Magnusson 1944}

Magnusson R. On the late results in non-operated cases of malleolar fractures: clinical-roentgenological-statistical 
study: fractures by external rotation. Acta Chirurgicaie Scandinavica 1944 [Suppl 84];90(1):1-36.

\section{Müller 1969}

Müller ME, Allgöwer M, Willenegger H. Manual der Osteosynthese, AO-technik. Berlin/Heidelberg/NewYork: Spinger Verlag, 1969.

\section{Müller 1979}

Müller ME, Allgöwer M, Schneider R, Willenegger $\mathrm{H}$. Manual of internal fixation: techniques recommended by the AO group. Second Edition. Berlin: Springer-Verlag, 1979.

\section{Müller 1990}

Muller ME, Nazarian S, Koch P, Schatzker J. The comprehensive classification of fractures of the long bones. Berlin/Heidelberg/New York: Springer Verlag, 1990.

\section{Olerud 1984}

Olerud C, Molander H. A scoring scale for symptom evaluation after ankle fracture. Archives of Orthopaedic \& Traumatic Surgery 1984;103(3):190-4. [PUBMED: 6437370]

\section{Petrisor 2006}

Petrisor BA, Poolman R, Koval K, Tornetta P 3rd, Bhandari M, Evidence-Based Orthopaedic Trauma Working Group. Management of displaced ankle fractures. Journal of Orthopaedic Trauma 2006;20(7):515-8. [PUBMED: 16891946]

\section{Ramasamy 2001}

Ramasamy PR. Comment on: J Bone Joint Surg Br. 2001 May;83(4):525-9. Journal of Bone and Joint Surgery - British Volume 2001;83:1084-6. [PUBMED: 11603529]

\section{Ramsey 1976}

Ramsey PL, Hamilton W. Changes in the tibiotalar area of contact caused by lateral shift. Journal of Bone and Joint Surgery - American Volume 1976;58(3):356-7. [PUBMED: 1262367 ]

\section{Rowley 1986a}

Rowley DI, Norris SH, Duckworth T. A prospective trial comparing operative and manipulative treatment of ankle fractures. Journal of Bone and Joint Surgery - British Volume 1986;68:610-3. [PUBMED: 3090049]

\section{Salai 2000a}

Salai M, Dudkieweicz I, Novikov I, Amit Y, Chechick A. The epidemic of ankle fractures in the elderly - is surgical treatment warranted?. Archives of Orthopaedic Trauma Surgery 2000;120:511-3. [PUBMED: 11011670]

SooHoo 2009

SooHoo NF, Krenek L, Eagan MJ, Gurbani B, Ko CY, Zingmond DS. Complication rates following open reduction and internal fixation of ankle fractures. Journal of Bone \& Joint Surgery - American Volume 2009;91(5): 1042-9. [PUBMED: 19411451 ]

\section{Stanton-Hicks 1995}

Stanton-Hicks M, Janig W, Hassenbusch S, Haddox JD, Boas R, WIlson P. Reflex sympathetic dystrophy: changing concepts and taxonomy. Pain 1995;63:127-33. [PUBMED: 8577483]

\section{Walsh 2004}

Walsh EF, DiGiovanni C. Fibular nonunion after closed rotational ankle fracture. Foot \& Ankle International 2004; 25(7):488-95. [PUBMED: 15319107]

\section{Weber 1972}

Weber BG. Die Verletzungen des oberen Sprunggelenkes. 2nd Edition. Bern: Huber, 1972.

\section{Wei 1999}

Wei SY, Okereke E, Winiarsky R, Lotke PA. Nonoperatively treated displaced bimalleolar and trimalleolar fractures: a 20-year follow-up. Foot \& Ankle International 1999;20(7): 404-7. [PUBMED: 10437921 ]

* Indicates the major publication for the study 


\section{CHARACTERISTICS OF STUDIES}

\section{Characteristics of included studies [ordered by study ID]}

\section{Bauer 1985}

\begin{tabular}{|c|c|}
\hline Methods & $\begin{array}{l}\text { Method of randomisation: random number tables. } \\
\text { Blinding: unclear. } \\
\text { Loss of follow-up: } 11 \text { ( } 7 \text { died, } 4 \text { lost to follow-up) out of } 111 \text {. However, type A fractures } \\
(\mathrm{n}=8) \text { are excluded in the analysis. The study reports the follow-up results of only the } \\
\text { type B fractures }(\mathrm{n}=92) \text {. } \\
\text { Patients' consent to randomisation: unclear. } \\
\text { Number of surgeons: } 10 \text { surgeons with at least one year of experience in fracture treatment } \\
\text { participated }\end{array}$ \\
\hline Participants & $\begin{array}{l}\text { Study locations: departments of orthopaedic surgery of the Malmö General Hospital in } \\
\text { Malmö and the Östersund Hospital in Östersund, both in Sweden } \\
\text { Study period: between } 1 \text { February } 1968 \text { and } 21 \text { June } 1970 \text {. } \\
\text { Study participants: } 111 \text { randomised, baseline data for } 108 \text {. Follow-up in } 92 \text { patients } \\
\text { Age: } 44 \text { years, range } 16 \text { to } 77 \text { years. } \\
\text { Gender: } 44 \text { men and } 64 \text { women (of which } 8 \text { patients with type A fractures are excluded) } \\
\text { Inclusion criteria: patients with a diagnosis of a malleolar fracture } \\
\text { Exclusion criteria: pilon fractures or tibial plafond fractures, type C fractures, patients } \\
\text { with open fractures, other concomitant injuries to the lower limb, nondisplaced fractures, } \\
\text { patients with open growth zones and those with diseases which entail increased risk of } \\
\text { complications }\end{array}$ \\
\hline
\end{tabular}

Interventions

Surgery: according to the AO principles (Müller 1979). Ligamentous injuries were sutured. Suction drainage as applied for 24 hours. Active movements started on the first postoperative day. The patients were kept in bed with the operated leg elevated in a splint until the fifth postoperative day. After 6 weeks, 20\% weight bearing was allowed. Full weight bearing was allowed after 9 weeks

Conservative: closed reduction was performed and a plaster cast was applied. The patients were discharged as soon as they were able to walk on crutches. Weight bearing was not allowed during the first 6 weeks in either group to prevent load-induced displacement. After 6 weeks, the cast was removed and $20 \%$ weight bearing was allowed. Full weight bearing was allowed after 12 weeks

A questionnaire (not validated and only introduced in the present study) measuring ankle girth, range of motion, presence of foot deformity, ability of walking, radiological outcome (bony union, anatomical result and osteoarthritis (according to Cedell (Cedell 1967) and Magnusson (Magnusson 1944)), hospital stay, mean time of treatment, sickleave, complications (infection, DVT, pulmonary embolism, tenderness)

Notes

Long-term results in this study only reported for displaced type B fractures. Early results were provided for 108 patients

Risk of bias

Surgical versus conservative interventions for treating ankle fractures in adults (Review) 
Bauer 1985 (Continued)

\begin{tabular}{|c|c|c|}
\hline Bias & Authors' judgement & Support for judgement \\
\hline $\begin{array}{l}\text { Random sequence generation (selection } \\
\text { bias) }\end{array}$ & Low risk & A list of random numbers was used. \\
\hline Allocation concealment (selection bias) & Unclear risk & $\begin{array}{l}\text { The authors only state: "random allocation } \\
\text { was performed with the aid of a list of random } \\
\text { numbers". }\end{array}$ \\
\hline $\begin{array}{l}\text { Blinding (performance bias and detection } \\
\text { bias) } \\
\text { All outcomes }\end{array}$ & High risk & $\begin{array}{l}\text { The authors state: "all films were evaluated } \\
\text { by the same radiologist" and "at follow-up all } \\
\text { patients were seen by two of the authors". }\end{array}$ \\
\hline $\begin{array}{l}\text { Incomplete outcome data (attrition bias) } \\
\text { All outcomes }\end{array}$ & Unclear risk & $\begin{array}{l}\text { The results at follow-up of } 8 \text { patients with } \\
\text { type A fractures were not incorporated } \\
\text { in the study. However baseline data were } \\
\text { shown. After exclusion of these } 8 \text { patients, } \\
\text { 'protocol deviants' were kept in their allo- } \\
\text { cated group }\end{array}$ \\
\hline Selective reporting (reporting bias) & Unclear risk & There is no study protocol available. \\
\hline Other bias & Unclear risk & No information to judge this. \\
\hline
\end{tabular}

Makwana 2001

Methods

Method of randomisation: computer-generated random numbers.

Blinding: unclear.

Loss of follow-up: 7 ( 6 unwilling to attend, 1 died) out of 43 (16\%). Eight (of which only 5 were available at follow-up) conservatively treated patients with secondary dislocation were excluded and not analysed (separately)

Patients' consent to randomisation: yes.

Number of surgeons: unknown number of registrars, senior registrars and consultants

Participants

Study location: level 1 trauma centre; Leicester Royal Infirmary, United Kingdom Study period: between January 1995 and February 1997.

Study participants: 43 randomised, baseline data for 43. Follow-up in 31 patients Age: 66 years, range 55 to 81 years.

Gender: 12 men and 31 women at baseline. Gender distribution at follow-up is unknown Inclusion criteria: all patients with a displaced ankle fracture over 55 years of age requiring operative treatment

Exclusion criteria: pre-existing ipsilateral or contralateral ankle pathology, a pathological fracture (e.g. a stress fracture), an intra-articular fracture (e.g. a pilon fracture), inability to attend follow-up or inability to follow the postoperative regimen, unsatisfactory closed reduction (according to criteria by Phillips (Phillips 1985)), blisters precluding operative treatment, pilon fractures or tibial plafond fractures 
Makwana 2001 (Continued)

\begin{tabular}{|c|c|}
\hline Interventions & $\begin{array}{l}\text { Surgery: standard AO implants and techniques according to the AO/ASIF manual } \\
\text { (Müller 1979). Additional information from correspondence (Ramasamy 2001): Nearly } \\
\text { all the fractures of the ankle ( } 96 \% \text { ) were fixed using a } 1 / 3 \text { semitubular plate on the lateral } \\
\text { side, with or without lag screws. In one patient the lateral malleolus was treated by a } \\
\text { Rush pin. AO cancellous screws were used in } 82 \% \text { of cases on the medial side, and this } \\
\text { was supplemented in one by a Kirschner wire. No fixation was necessary in three medial } \\
\text { malleoli. Postoperative regimen: a below-knee cast was retained for six weeks. The leg } \\
\text { was elevated for } 48 \text { hours after which protected weight-bearing was allowed } \\
\text { Conservative: a moulded below-knee plaster cast, with } 48 \text { hours limb elevation, after } \\
\text { which protected weight-bearing was allowed for } 6 \text { weeks }\end{array}$ \\
\hline Outcomes & $\begin{array}{l}\text { Length of follow-up: mean } 27 \text { months, range } 15 \text { to } 42 \text { months. } \\
\text { Olerud and Molander ankle score (Olerud 1984), visual analogue score for pain, an- } \\
\text { kle girth, range of motion, inpatient stay, radiological outcome (bony union, malu- } \\
\text { nion, nonunion, talar tilt and degenerative changes using the criteria of Magnusson } \\
\text { (Magnusson 1944)), complications (wound problems, tenderness of the scar, malunion, } \\
\text { nonunion, Complex Regional Pain Syndrome type } 1 \text { (Stanton-Hicks 1995), secondary } \\
\text { dislocation and further surgery). }\end{array}$ \\
\hline
\end{tabular}

Notes

It is unclear from the report whether there were 47 randomised patients (Abstract states: "Forty-seven patients ... were entered into a prospective, randomised study") or 43 (according to the flow chart and 'Patients and methods section', where randomisation occurred after assessment of a satisfactory closed reduction). We have opted for the latter

Risk of bias

\begin{tabular}{lll}
\hline Bias & Authors' judgement & Support for judgement \\
\hline $\begin{array}{l}\text { Random sequence generation (selection } \\
\text { bias) }\end{array}$ & Low risk & $\begin{array}{l}\text { A computer random number generator was } \\
\text { used. }\end{array}$ \\
\hline Allocation concealment (selection bias) & Unclear risk & $\begin{array}{l}\text { The authors only state: "patients had been } \\
\text { randomised by computer-generated random } \\
\text { numbers in theatre". }\end{array}$ \\
\hline
\end{tabular}

Blinding (performance bias and detection High risk bias)

All outcomes

Incomplete outcome data (attrition bias) High risk All outcomes
The authors only state: "all patients were assessed clinically and radiographically by the same observer (first author) at follow-up in order to minimise interobserver error".

Of the 22 patients in the ORIF group only 19 had successful manipulative reduction; the 3 patients with unsuccessful reduction were excluded, because they required surgery. Eight (of which only 5 were available at follow-up) conservatively treated patients with secondary dislocation were excluded and not analysed (separately). No 
Makwana 2001 (Continued)

intention-to-treat-analysis was performed

\begin{tabular}{|c|c|c|}
\hline Selective reporting (reporting bias) & Unclear risk & There is no study protocol available. \\
\hline Other bias & High risk & $\begin{array}{l}\text { The conservative group had significantly } \\
\text { more smokers ( } 6 \text { versus } 0)\end{array}$ \\
\hline
\end{tabular}

Phillips 1985

$\begin{array}{ll}\text { Methods } & \text { Method of randomisation: random number tables. } \\ \text { Blinding: unclear. } & \text { Loss of follow-up: } 47 \text { (could not be located or refused to be evaluated) of } 96 \text { (49\%) } \\ \text { Patients' consent to randomisation: yes. } \\ \text { Number of surgeons: two members of the attending orthopaedic staff in combination } \\ \text { with a resident }\end{array}$

Interventions

There were two treatment categories relevant to this review:

Surgery: satisfactory closed reduction and then open reduction and internal fixation by the Association for the Study of Internal Fixation (ASIF) technique. The leg was immobilised in a below-the-knee plaster cast. Walking on crutches without weight bearing started a few days after surgery until the tenth week. The cast was removed after 1 week to allow early active motion exercises. The trans-syndesmotic screw (if present) was removed after 10 weeks

Conservative: satisfactory closed reduction followed by continued closed treatment. A toe-to-thigh cast with the knee flexed in 30 degrees was applied for 6 weeks, without weight-bearing. At the end of 6 weeks a below-the-knee walking cast was applied for an additional 4 weeks

Outcomes

Length of follow-up: 3.5 years, range 1.7 to 6.0 years.

The authors devised 3 scoring systems for this study that provided clinical (maximum 100 points for pain, range of motion and function), anatomical (maximum 35 points for talocrural angle, medial clear space, integrity of tibiofibular syndesmosis, medial malleolar displacement, size of posterior malleolar fragment, lateral malleolar displacement and shortening, talar tilt, talar subluxation, aspect of anteromedial corner) and arthritis scores (maximum15 points for non-union, synostosis, osteoporosis, irregular articular

Surgical versus conservative interventions for treating ankle fractures in adults (Review) 
surface, osteophytes, periarticular cysts and joint-space narrowing). These three scores were combined to give a total score, for which a perfect result was 150 points.

Complications (secondary operation; pressure sores; superficial skin sloughs; non-union; deep infection)

Death (post-operative)

Notes

The trial also compared two methods of surgery where there was unsatisfactory closed reduction in 42 patients (open reduction and internal fixation by the ASIF technique versus open reduction and internal fixation of the medial malleolus). These groups are not included in this review

Risk of bias

\begin{tabular}{l|lll}
\hline Bias & Authors' judgement & Support for judgement \\
\hline $\begin{array}{l}\text { Random sequence generation (selection } \\
\text { bias) }\end{array}$ & Low risk & A random numbers table was used. \\
\hline $\begin{array}{l}\text { Allocation concealment (selection bias) } \\
\text { Blinding (performance bias and detection } \\
\text { bias) } \\
\text { All outcomes }\end{array}$ & Low risk & Sealed envelopes were used. \\
\hline $\begin{array}{l}\text { Incomplete outcome data (attrition bias) } \\
\text { All outcomes }\end{array}$ & High risk & $\begin{array}{l}\text { No information about blinding is provided } \\
\text { in the study. }\end{array}$ \\
\hline $\begin{array}{l}\text { Selective reporting (reporting bias) } \\
\text { Other bias }\end{array}$ & Unclear risk & $\begin{array}{l}\text { In } 47 \text { patients follow-up could not be per- } \\
\text { formed because patients could not be lo- } \\
\text { cated or refused to be evaluated. In three of } \\
\text { these patients baseline characteristics could } \\
\text { not be provided, because of the loss of their } \\
\text { charts }\end{array}$ \\
\hline
\end{tabular}

Rowley 1986

Methods

A quasi-randomised study using Accident and Emergency number Blinding: unclear.

Loss of follow-up: 2 (excluded because of open reduction and internal fixation after failed manipulation) of $42(5 \%)$

Patients' consent to randomisation: unclear.

Number of surgeons: unclear.

Participants

Study location: The Royal Hallamshire Hospital, University of Sheffield, United Kingdom

Study period: unclear.

Study participants: 42 randomised, no baseline characteristics provided (only type of 
fracture). Follow-up in 40 patients

Age: mean not provided, range 16 to 70 years.

Gender: not provided.

Inclusion criteria: patients with a diagnosis of a displaced type ankle fracture

Exclusion criteria: patients with pilon or tibial plafond fracture

Interventions

Surgery: Open reduction and internal fixation, using the standard AO technique (Müller 1979), fixing the fibula with compression screws and a buttress plate, and the medial malleolus with screws or tension bands according to the fragment size. No attempt was made to institute any ligamentous repair. After fixation, the limb was placed in a below-knee backslab; early active movement was started on the first day after operation and continued for five days until a reasonable range of movement was established. The ankle was then placed in a below-knee plaster for 6 weeks and early weight-bearing was encouraged. At 6 weeks, patients were mobilised out of plaster and weight bearing was encouraged as soon as possible. No formal physiotherapy was offered

Conservative: After manipulation, the position of the fracture was subsequently maintained in a long-leg plaster for 6 weeks and early weight-bearing was encouraged. The criteria of a good reduction were defined as correction of talar shift on the anterolateral radiograph and of posterior talar subluxation on the lateral film. On both views, the fibula had to be corrected in terms of rotation and length. The medial malleolus had to have a smooth articular profile, although a small step on its medial aspect was acceptable. Further radiographs were taken at one and two weeks from injury; if there was significant loss of position the patient was re-admitted and open reduction and internal fixation was carried out. At 6 weeks, patients were mobilised out of plaster and weight bearing was encouraged as soon as possible. No formal physiotherapy was offered

Outcomes

Length of follow-up: 20 weeks, no range provided.

Time to normal weight-bearing. Time for dorsiflexion to return to normal. Time for foot angle to return to normal (the position of the foot during walking by means of a footprint analysis).

Complications (none)

Treatment failure

Notes

Risk of bias

\begin{tabular}{|c|c|c|}
\hline Bias & Authors' judgement & Support for judgement \\
\hline $\begin{array}{l}\text { Random sequence generation (selection } \\
\text { bias) }\end{array}$ & High risk & $\begin{array}{l}\text { The study was quasi-randomised according } \\
\text { to the last digit of the Accident and Emer- } \\
\text { gency number }\end{array}$ \\
\hline
\end{tabular}

Allocation concealment (selection bias) High risk

The authors provide no information about allocation concealment and was quasi-randomised

Blinding (performance bias and detection High risk No information about blinding is provided bias)

in the study.

Surgical versus conservative interventions for treating ankle fractures in adults (Review) 


\section{Rowley 1986 (Continued)}

\begin{tabular}{|c|c|c|}
\hline All outcomes & & \\
\hline $\begin{array}{l}\text { Incomplete outcome data (attrition bias) } \\
\text { All outcomes }\end{array}$ & Low risk & $\begin{array}{l}\text { Two patients were excluded in the analysis, } \\
\text { because they required secondary surgery af- } \\
\text { ter failed manipulation. The authors' in- } \\
\text { tention was to analyse these patients sep- } \\
\text { arately, but this was not done. The effects } \\
\text { of these two missing patients were explored } \\
\text { in analysis } 1.2 \text { and revealed no significant } \\
\text { impact on the results }\end{array}$ \\
\hline Selective reporting (reporting bias) & Unclear risk & There is no study protocol available. \\
\hline Other bias & Unclear risk & No information to judge this. \\
\hline
\end{tabular}

\section{Characteristics of excluded studies [ordered by study ID]}

\begin{tabular}{|c|c|}
\hline Study & Reason for exclusion \\
\hline Dietrich 2002 & Not a randomised controlled trial. \\
\hline Doleż al 1995 & Not a randomised controlled trial. \\
\hline Hughes 1979 & $\begin{array}{l}\text { Not a randomised controlled trial. Depending on the hospital of presentation patients received only operative } \\
\text { treatment (Kantonsspittal-St. Gallen, Switzerland) or conservative and operative treatment (University Surgery } \\
\text { Clinic, Freiburg, Germany and Kantonsspital-Liestal, Switzerland) }\end{array}$ \\
\hline Richter 1994 & Not a randomised controlled trial. \\
\hline Salai 2000 & $\begin{array}{l}\text { The absence of clarification of study methods from the trial author has failed to convince us that this was a } \\
\text { randomised trial. Even if it was randomised, the reported results from the study could not be used given that the } \\
\text { data from } 19 \text { surgically-treated patients who "met the above criteria for randomisation" were combined with } 30 \\
\text { other surgically-treated patients, and compared with those of "an additional } 16 \text { [who] completed treatment by } \\
\text { closed reduction" }\end{array}$ \\
\hline Strömsöe 1995 & $\begin{array}{l}\text { This randomised controlled trial including patients with an unstable Weber B or C ankle fracture without a medial } \\
\text { malleolar fracture compared different surgical approaches. No patients were treated conservatively }\end{array}$ \\
\hline Velkovski 1995 & Not a randomised controlled trial. \\
\hline Yde 1980a & $\begin{array}{l}\text { Not a randomised controlled trial. Depending on the hospital of presentation, patients with supination-eversion } \\
\text { stage II fractures received conservative treatment (Fredrikhavn Hospital, Denmark) or operative treatment (Hjørring } \\
\text { Hospital, Denmark) }\end{array}$ \\
\hline
\end{tabular}


(Continued)

Yde 1980b Not a randomised controlled trial. Depending on the hospital of presentation, patients with supination-eversion stage IV fractures received conservative treatment (Fredrikhavn Hospital, Denmark) or operative treatment (Hjørring Hospital, Denmark)

\section{Characteristics of ongoing studies [ordered by study ID]}

\section{Gray}

Trial name or title Influence of ankle skin perfusion on fracture treatment outcomes in the elderly: a randomised controlled trial comparing total contact cast with open reduction and internal fixation, the effect on cutaneous blood supply and relationship to skin complications

\begin{tabular}{ll}
\hline Methods & Randomised interventional trial \\
\hline Participants & $\begin{array}{l}\text { Patients aged over } 60 \text { years old with an unstable ankle fracture } \\
\text { Estimated enrolment: } 120 .\end{array}$ \\
\hline Interventions & $\begin{array}{l}\text { Patients will be anaesthetised and undergo either closed manipulation of the fracture and then application of } \\
\text { a close contact cast or have a surgical open reduction and internal fixation by a contemporary method using } \\
\text { metal plates and screws }\end{array}$ \\
\hline Outcomes & $\begin{array}{l}\text { Olerud and Molander score, skin complications, radiological assessment, quality of life at } 6 \text { weeks and } 6 \\
\text { months }\end{array}$ \\
\hline Starting date & May 2004 \\
\hline Contact information & $\begin{array}{l}\text { Gray B, Kadoorie Centre for Critical Care Research, Level 3, Headley Way, Headington, Oxford, United } \\
\text { Kingdom, OX3 9DU }\end{array}$ \\
\hline Notes & Expected end date: 2010 \\
\hline
\end{tabular}

\section{Harris}

\begin{tabular}{ll}
$\begin{array}{l}\text { Trial name or title } \\
\text { Methods }\end{array}$ & Combined randomised and observational study of type B ankle fracture treatment (CROSSBAT) \\
\hline Participants & $\begin{array}{l}\text { Patients aged between } 18 \text { and } 65 \text { years with a diagnosis of undisplaced (AO type 44-B1) distal fibula fracture } \\
\text { Estimated enrolment: } 160\end{array}$ \\
\hline Interventions & Operative versus non operative treatment \\
\hline Outcomes & $\begin{array}{l}\text { American Academy of Orthopaedic Surgeons (AAOS) Foot and Ankle Questionnaire and SF-12 version 2 } \\
\text { Health Survey }\end{array}$ \\
\hline $\begin{array}{l}\text { Starting date } \\
\text { August } 2010\end{array}$ \\
\hline $\begin{array}{l}\text { Surgical versus conservative interventions for treating ankle fractures in adults (Review) } \\
\text { Copyright } \odot \mathbf{2 0 1 2} \text { The Cochrane Collaboration. Published by John Wiley \& Sons, Ltd. }\end{array}$
\end{tabular}




\section{Harris (Continued)}

\begin{tabular}{ll} 
Contact information & $\begin{array}{l}\text { Mittal R, Bsc (Med), MBB, The University of New South Wales, Australia, +61 2 9828 3947, rajatmittal. } \\
\text { syd@gmail.com }\end{array}$ \\
\hline Notes & December 2016 \\
\hline
\end{tabular}

\section{Pakarinen}

\begin{tabular}{ll}
\hline Trial name or title & Syndesmotic injury and fixation in supination-external (SE) ankle fractures \\
\hline Methods & Randomised controlled trial \\
\hline Participants & $\begin{array}{l}\text { All skeletally mature patients }(\geq 16 \text { years old) with a unilateral Lauge-Hansen supination-external rotation } \\
\text { type } 4 \text { ankle fractures treated within one week after injury at their hospital } \\
\text { Estimated enrolment: } 140\end{array}$ \\
\hline Interventions & Comparing syndesmotic transfixation to no fixation in AO/OTA Weber B-type ankle fracture \\
\hline Outcomes & $\begin{array}{l}\text { Olerud-Molander scoring system, RAND 36-Item Health Survey, and visual analogue scale (VAS) to measure } \\
\text { pain and function after a minimum 1-year of follow-up }\end{array}$ \\
\hline Starting date & June 2007 \\
\hline Contact information & Pakarinen HJ, Oulu University Hospital, Finland \\
\hline Notes & Expected end date: 2010 \\
\hline
\end{tabular}

Sanders

\begin{tabular}{ll}
\hline Trial name or title & Operative versus non operative treatment for unstable ankle fractures \\
\hline Methods & A prospective randomised multi-centre study \\
\hline Participants & $\begin{array}{l}\text { Patients aged between } 18 \text { and } 65 \text { years with a diagnosis of unstable Weber B unilateral fibular fracture } \\
\text { Estimated enrolment: } 80\end{array}$ \\
\hline Interventions & Operative versus non operative treatment \\
\hline Outcomes & Comparison of physical functioning score on SF36 \\
\hline Starting date & November 2001 \\
\hline Contact information & Sanders D, M.D., FRCSC, University of Western Ontario, Canada, 519-685-8055 \\
\hline Notes & Expected end date: 2010 \\
\hline
\end{tabular}


Willett

Trial name or title Comparison of close contact cast (CCC) technique to open surgical reduction and internal fixation (ORIF) in the treatment of unstable ankle fractures in patients over 60 years

Methods Multi-centre pragmatic individually randomised controlled equivalence study

Participants Patients aged over 60 years with a diagnosis of an isolated displaced unstable ankle fracture

Estimated enrolment: 620

Interventions Close contact cast versus open reduction and internal fixation

Outcomes Olerud and Molander ankle score, Iowa ankle score, radiological measurements of fracture and ankle joint congruence, Euroqol EQ-5D and SF-12 health survey

Starting date October 2009

Contact information Prof. K. Willett, Kadoorie Centre John Radcliffe Hospital, OX3 9DU, University of Oxford, United Kingdom

Notes

Expected end date: 2014 
DATA AND ANALYSES

\section{Comparison 1. Surgical versus conservative treatment}

\begin{tabular}{|c|c|c|c|c|}
\hline Outcome or subgroup title & $\begin{array}{l}\text { No. of } \\
\text { studies }\end{array}$ & $\begin{array}{c}\text { No. of } \\
\text { participants }\end{array}$ & Statistical method & Effect size \\
\hline $\begin{array}{l}1 \text { Complaints of symptoms (pain, } \\
\text { restricted range of ankle } \\
\text { motion, unsteadiness, swelling) } \\
\text { and walking difficulties at } 7 \\
\text { years }\end{array}$ & 1 & & Risk Ratio (M-H, Fixed, 95\% CI) & Totals not selected \\
\hline $\begin{array}{l}\text { 1.1 Complaints of significant } \\
\text { symptoms }\end{array}$ & 1 & & Risk Ratio (M-H, Fixed, 95\% CI) & $0.0[0.0,0.0]$ \\
\hline 1.2 Pain & 1 & & Risk Ratio (M-H, Fixed, 95\% CI) & $0.0[0.0,0.0]$ \\
\hline 1.3 Restricted range of motion & 1 & & Risk Ratio (M-H, Fixed, 95\% CI) & $0.0[0.0,0.0]$ \\
\hline 1.4 Unsteadiness & 1 & & Risk Ratio (M-H, Fixed, 95\% CI) & $0.0[0.0,0.0]$ \\
\hline 1.5 Swelling & 1 & & Risk Ratio (M-H, Fixed, 95\% CI) & $0.0[0.0,0.0]$ \\
\hline 1.6 Passing stiffness & 1 & & Risk Ratio (M-H, Fixed, 95\% CI) & $0.0[0.0,0.0]$ \\
\hline $\begin{array}{l}1.7 \text { Walking difficulties on } \\
\text { rough ground }\end{array}$ & 1 & & Risk Ratio (M-H, Fixed, 95\% CI) & $0.0[0.0,0.0]$ \\
\hline $\begin{array}{l}\text { 1.8 Walking difficulties on } \\
\text { even ground }\end{array}$ & 1 & & Risk Ratio (M-H, Fixed, 95\% CI) & $0.0[0.0,0.0]$ \\
\hline 2 Functional or combined scores & 2 & & Mean Difference (IV, Fixed, 95\% CI) & Totals not selected \\
\hline $\begin{array}{l}2.1 \text { Olerud scores at mean } 27 \\
\text { months ( } 0 \text { to } 100 \text { : best score) }\end{array}$ & 1 & & Mean Difference (IV, Fixed, 95\% CI) & $0.0[0.0,0.0]$ \\
\hline $\begin{array}{l}2.2 \text { Combined (clinical, } \\
\text { anatomical + arthritis: } 0 \text { to } 150 \text { : } \\
\text { best) scores at mean } 3.5 \text { years }\end{array}$ & 1 & & Mean Difference (IV, Fixed, 95\% CI) & $0.0[0.0,0.0]$ \\
\hline $\begin{array}{l}3 \text { Pain scores (VAS: assume } \\
\text { maximum of 100: worst) at } \\
\text { mean of } 27 \text { months }\end{array}$ & 1 & & Mean Difference (IV, Fixed, 95\% CI) & Totals not selected \\
\hline 4 Adverse events & 4 & & Risk Ratio (M-H, Fixed, 95\% CI) & Subtotals only \\
\hline $\begin{array}{l}\text { 4.1 Early treatment failure } \\
\text { (usually secondary operation) }\end{array}$ & 4 & 242 & Risk Ratio (M-H, Fixed, 95\% CI) & $0.18[0.06,0.54]$ \\
\hline $\begin{array}{l}\text { 4.2 Deep / more serious } \\
\text { infection }\end{array}$ & 3 & 172 & Risk Ratio (M-H, Fixed, 95\% CI) & $0.23[0.01,4.61]$ \\
\hline 4.3 Superficial infection & 3 & 172 & Risk Ratio (M-H, Fixed, 95\% CI) & $0.97[0.21,4.37]$ \\
\hline 4.4 Skin ulcer $(s)$ & 2 & 80 & Risk Ratio (M-H, Fixed, 95\% CI) & $0.22[0.03,1.93]$ \\
\hline 4.5 Deep vein thrombosis & 1 & 92 & Risk Ratio (M-H, Fixed, 95\% CI) & $0.76[0.13,4.34]$ \\
\hline $\begin{array}{l}\text { 4.6 Complex regional pain } \\
\text { syndrome }\end{array}$ & 1 & 31 & Risk Ratio (M-H, Fixed, 95\% CI) & $3.25[0.17,62.40]$ \\
\hline 4.7 Wound closure problem & 1 & 31 & Risk Ratio (M-H, Fixed, 95\% CI) & $1.95[0.09,44.32]$ \\
\hline $\begin{array}{l}\text { 4.8 Removal of internal } \\
\text { fixation }\end{array}$ & 1 & 31 & Risk Ratio (M-H, Fixed, 95\% CI) & $4.55[0.26,81.03]$ \\
\hline 4.9 Surgical scar tenderness & 1 & 31 & Risk Ratio (M-H, Fixed, 95\% CI) & $3.25[0.17,62.40]$ \\
\hline $\begin{array}{l}5 \text { Functional impairment at } 20 \\
\text { weeks }\end{array}$ & 1 & & Risk Ratio (M-H, Fixed, 95\% CI) & Totals not selected \\
\hline 5.1 Restricted dorsiflexion & 1 & & Risk Ratio (M-H, Fixed, 95\% CI) & $0.0[0.0,0.0]$ \\
\hline 5.2 Abnormal foot angle & 1 & & Risk Ratio (M-H, Fixed, 95\% CI) & $0.0[0.0,0.0]$ \\
\hline
\end{tabular}


6 Differences in range of motion

(injured ankle - other ankle)

6.1 Dorso-plantar (degrees)

6.2 Dorsiflexion (degrees)

6.3 Pro-supination (degrees)

7 Radiological results: non-union and malunion

7.1 Non union

7.2 Malunion

8 Radiological signs of osteoarthritis

8.1 Findings at mean of 7 years

8.2 Findings at mean of 3.5 years

9 Length of hospital stay (days)
Mean Difference (IV, Fixed, 95\% CI)

Mean Difference (IV, Fixed, 95\% CI)

Mean Difference (IV, Fixed, 95\% CI)

Mean Difference (IV, Fixed, 95\% CI)

Risk Ratio (M-H, Fixed, 95\% CI)

Risk Ratio (M-H, Fixed, 95\% CI)

Risk Ratio (M-H, Fixed, 95\% CI)

Risk Ratio (M-H, Fixed, 95\% CI)

Risk Ratio (M-H, Fixed, 95\% CI)

49

Risk Ratio (M-H, Fixed, 95\% CI)

Mean Difference (IV, Fixed, 95\% CI)
Totals not selected

$0.0[0.0,0.0]$

$0.0[0.0,0.0]$

$0.0[0.0,0.0]$

Totals not selected

$0.0[0.0,0.0]$

$0.0[0.0,0.0]$

$1.05[0.83,1.31]$

$1.10[0.84,1.45]$

$0.94[0.64,1.40]$

Totals not selected

\section{Analysis I.I. Comparison I Surgical versus conservative treatment, Outcome I Complaints of symptoms (pain, restricted range of ankle motion, unsteadiness, swelling) and walking difficulties at 7 years.}

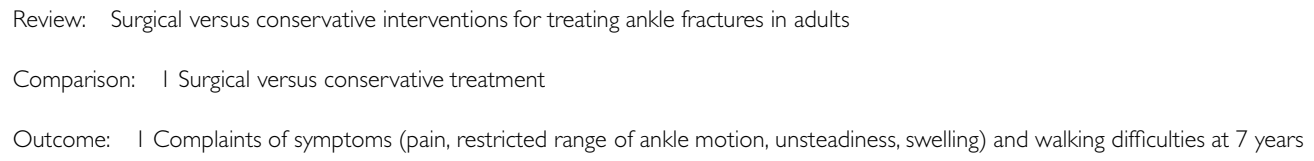

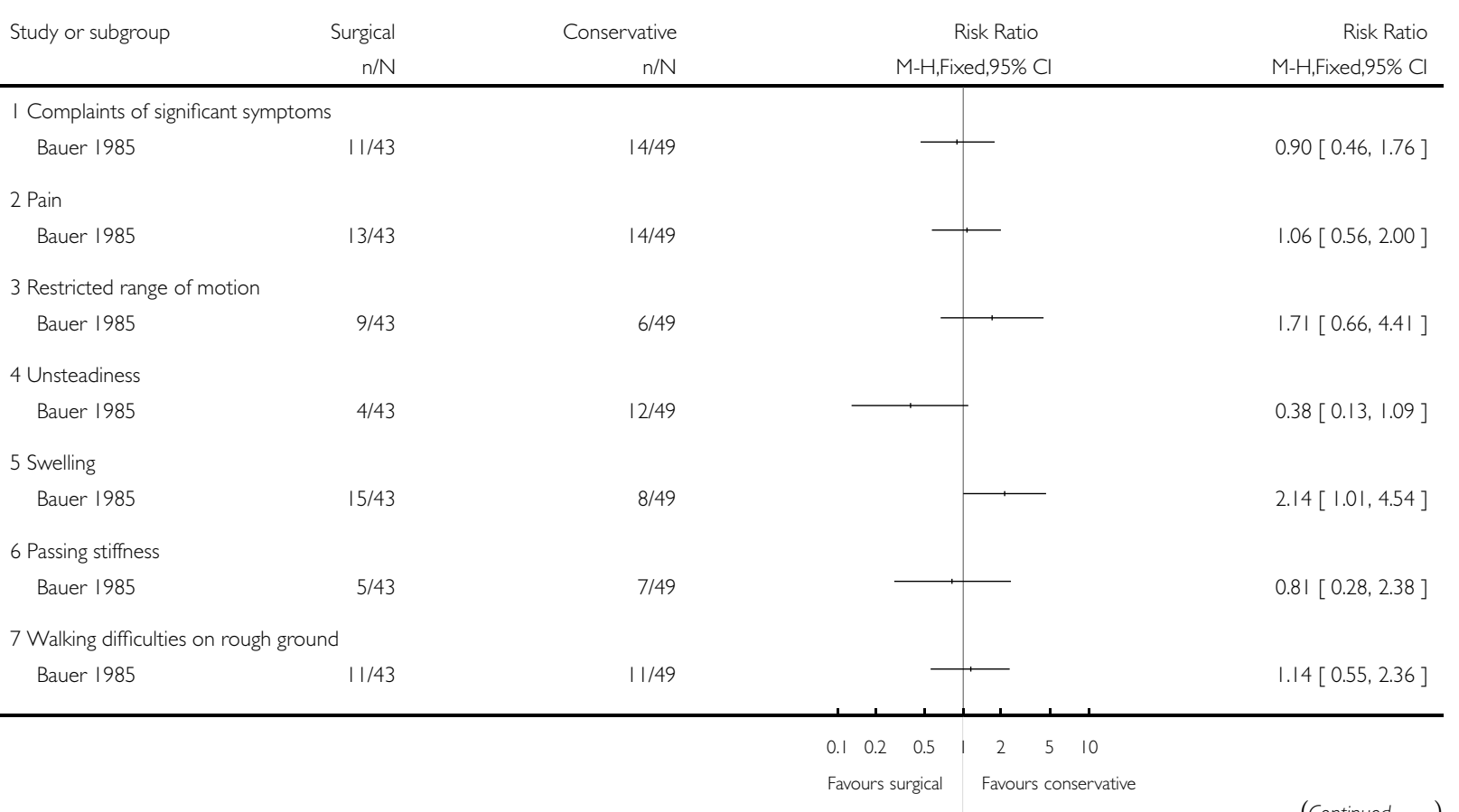




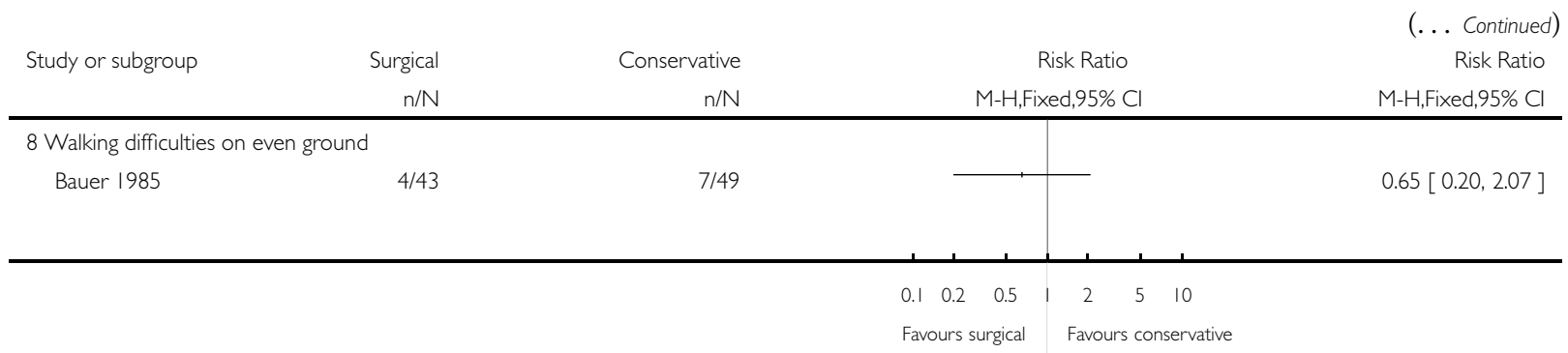

\section{Analysis I.2. Comparison I Surgical versus conservative treatment, Outcome 2 Functional or combined} scores.

Review: Surgical versus conservative interventions for treating ankle fractures in adults

Comparison: I Surgical versus conservative treatment

Outcome: 2 Functional or combined scores

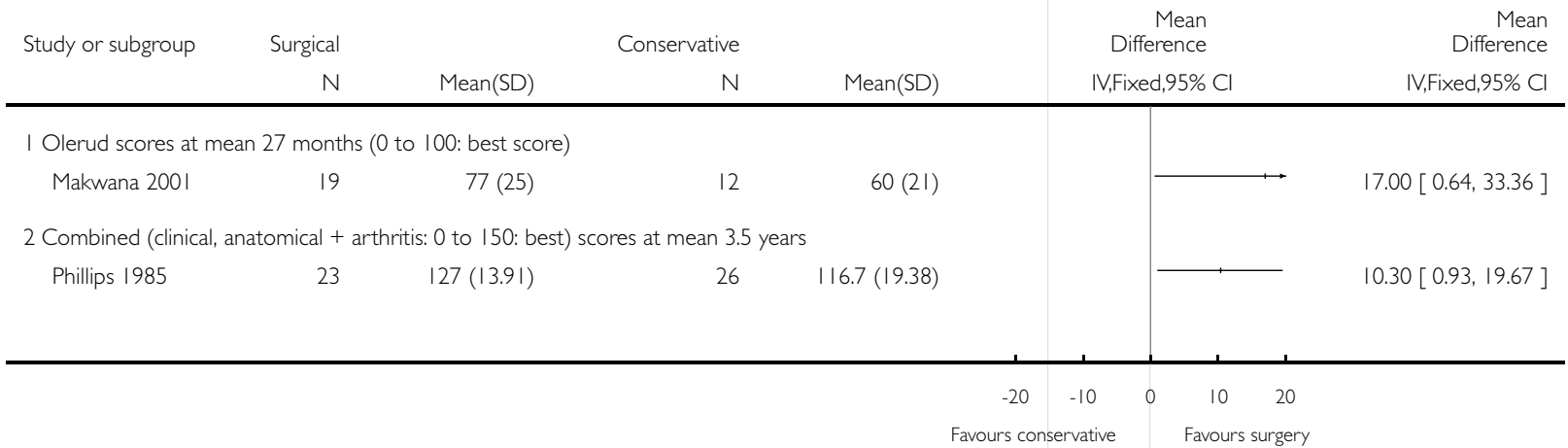




\section{Analysis I.3. Comparison I Surgical versus conservative treatment, Outcome 3 Pain scores (VAS: assume} maximum of 100: worst) at mean of 27 months.

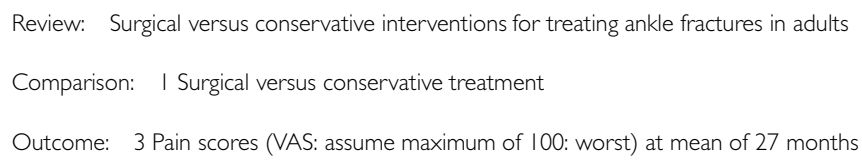

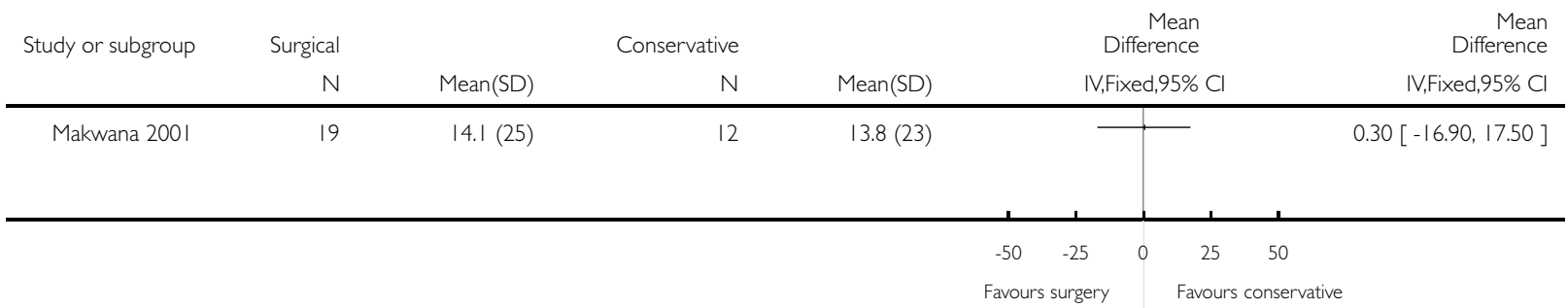

\section{Analysis I.4. Comparison I Surgical versus conservative treatment, Outcome 4 Adverse events.}

Review: Surgical versus conservative interventions for treating ankle fractures in adults

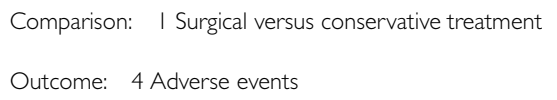

(1)

Makwana 200 I

Phillips 1985

Subtotal (95\% CI)

\section{$8 / 57$}

$8 / 21$

$1 / 26$

$2 / 22$

126

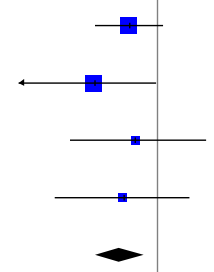

Total events: 2 (Surgical), 19 (Conservative)

Heterogeneity: $\mathrm{Chi}^{2}=1.21, \mathrm{df}=3(\mathrm{P}=0.75) ; \mathrm{I}^{2}=0.0 \%$

Test for overall effect: $Z=3.05(P=0.0023)$

2 Deep / more serious infection

Bauer 1985
$0 / 43$
$2 / 49$
$37.7 \%$

$43.4 \%$

$7.0 \%$

$11.9 \%$

$100.0 \%$ M-H,Fixed,95\% Cl

\begin{tabular}{lllllllll}
0.002 & 0.1 & 1 & 10 & 500 \\
\hline & Favours surgical & Favours conservative
\end{tabular}

(Continued ...) 


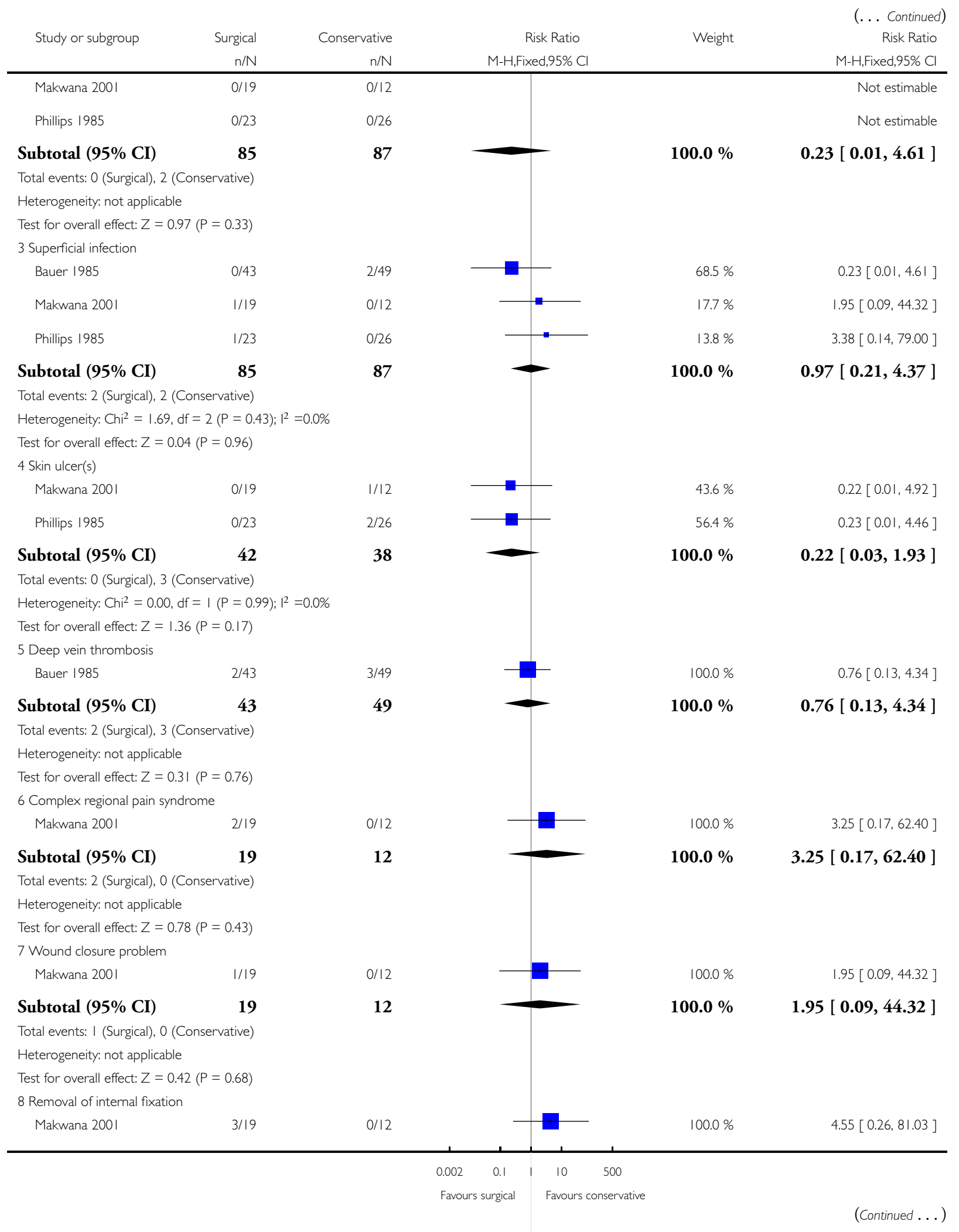

Surgical versus conservative interventions for treating ankle fractures in adults (Review) 


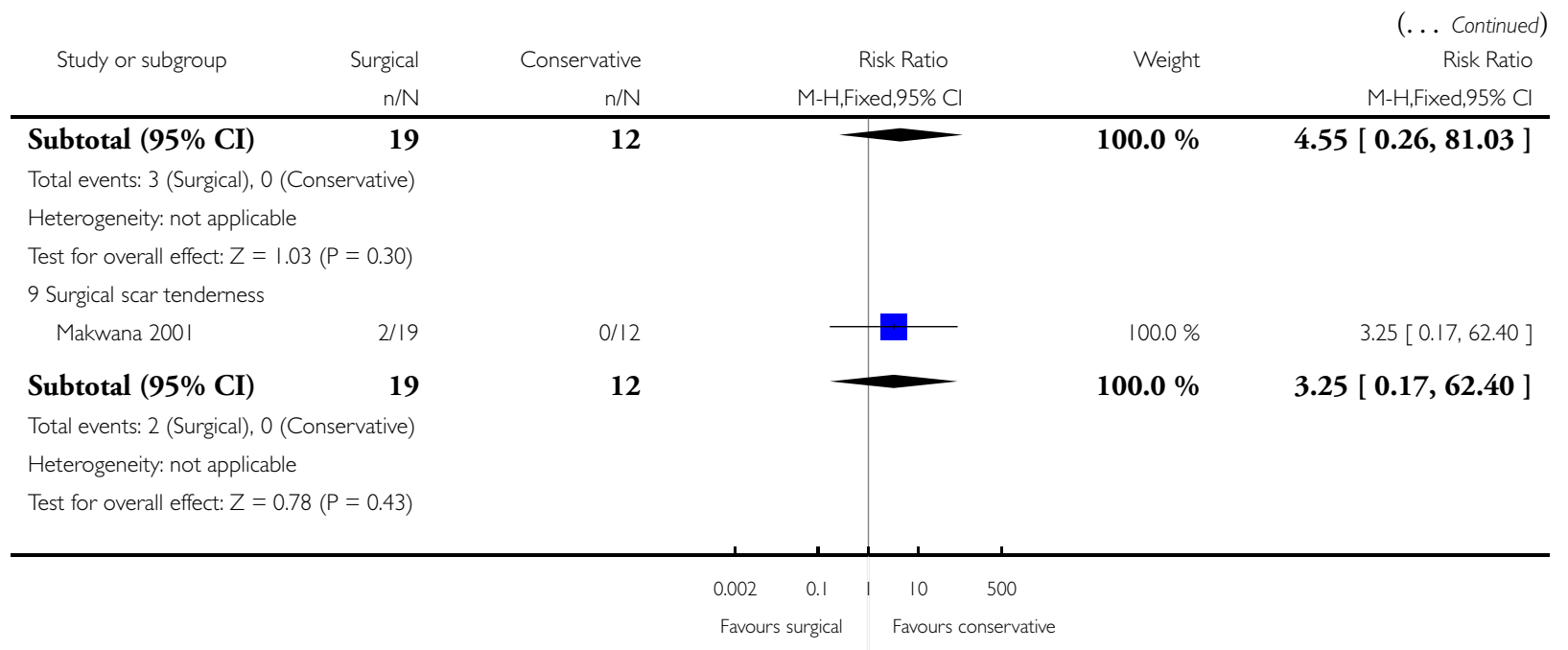

\section{Analysis I.5. Comparison I Surgical versus conservative treatment, Outcome 5 Functional impairment at 20 weeks.}

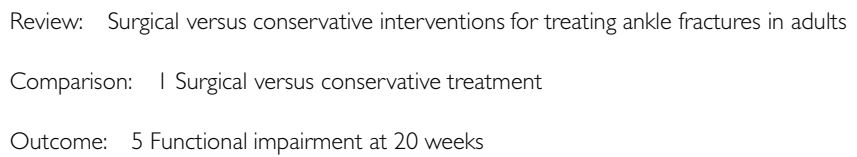

| Restricted dorsiflexion

Rowley 1986

$4 / 20$

$3 / 20$

2 Abnormal foot angle

Rowley 1986

$7 / 20$

$2 / 20$

$1.33[0.34,5.21]$

$3.50[0.83,14.83]$ 


\section{Analysis I.6. Comparison I Surgical versus conservative treatment, Outcome 6 Differences in range of} motion (injured ankle - other ankle).

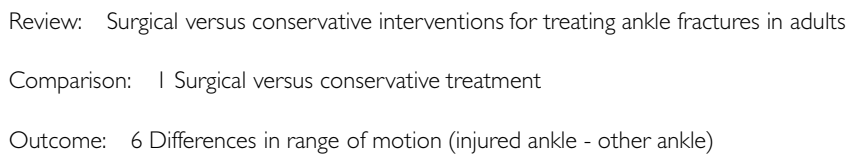

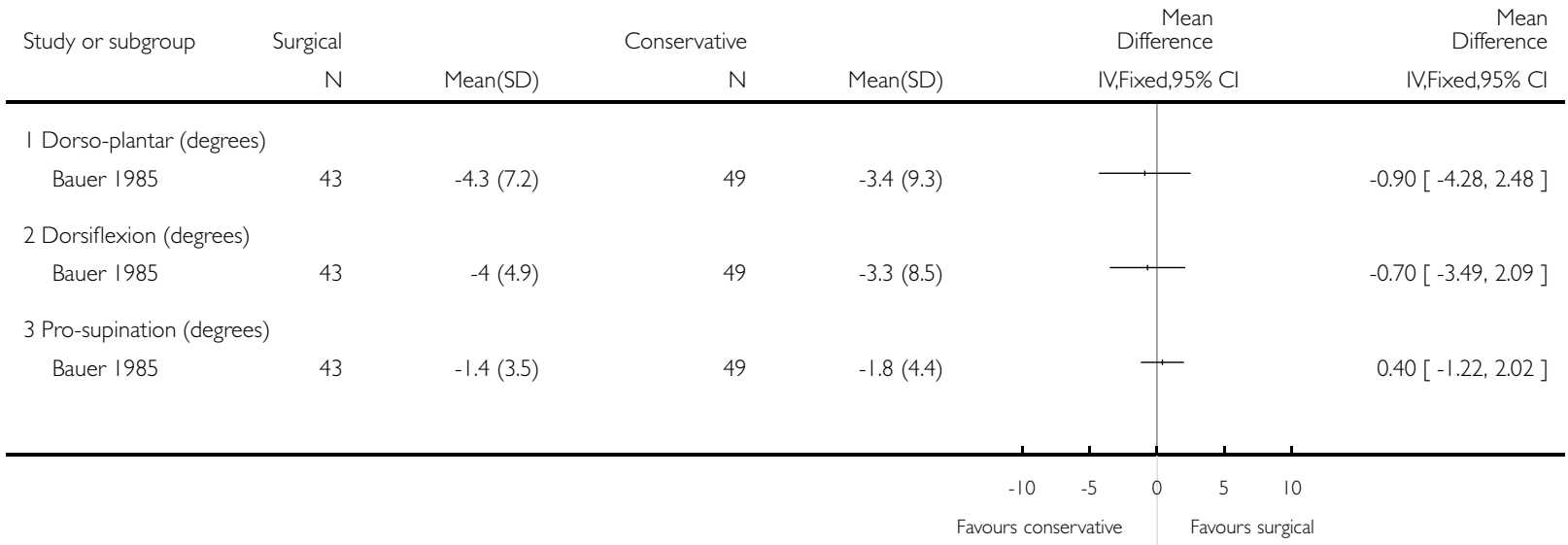


Analysis I.7. Comparison I Surgical versus conservative treatment, Outcome 7 Radiological results: nonunion and malunion.

Review: Surgical versus conservative interventions for treating ankle fractures in adults

Comparison: I Surgical versus conservative treatment

Outcome: 7 Radiological results: non-union and malunion

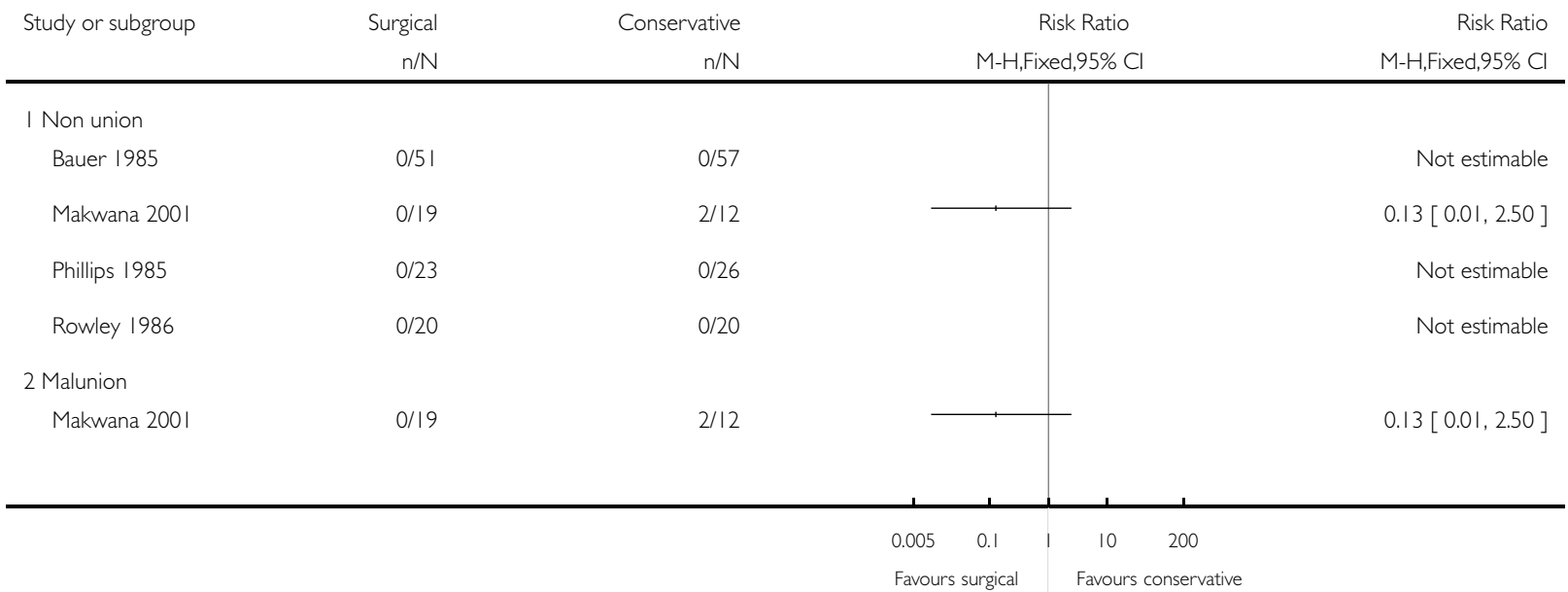


Analysis I.8. Comparison I Surgical versus conservative treatment, Outcome 8 Radiological signs of osteoarthritis.

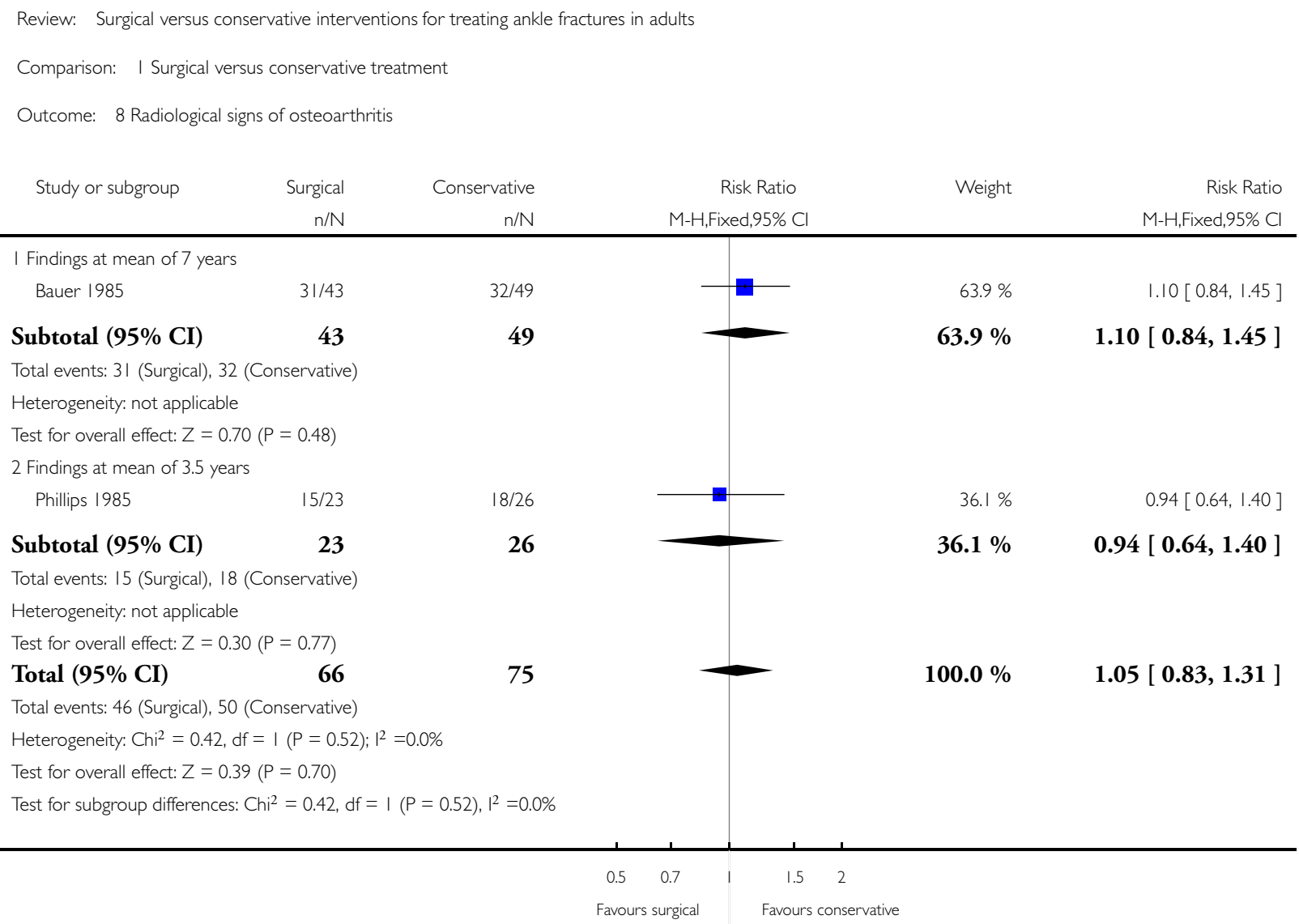




\section{Analysis I.9. Comparison I Surgical versus conservative treatment, Outcome 9 Length of hospital stay} (days).

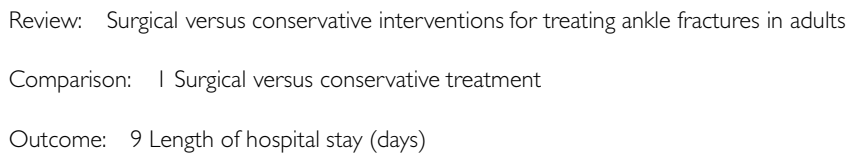

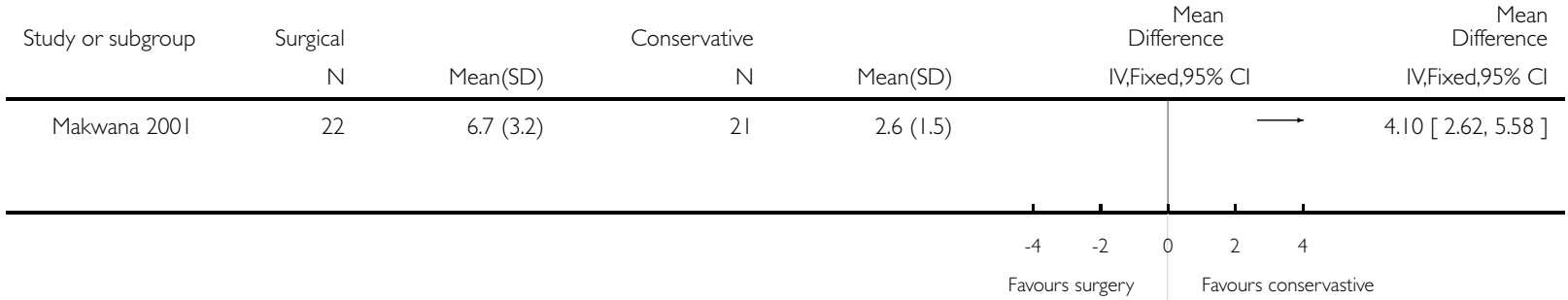

\section{A P P E N D I C E S}

\section{Appendix I. Search strategies}

\section{MEDLINE (PubMed)}

\#1: Ankle Injuries[MeSH] OR Ankle[MeSH] OR Ankle Joint[MeSH]

\#2: Fractures, Bone[MeSH] OR Fracture Healing[MeSH] OR Fracture Fixation[MeSH]

\#3: \#1 AND \#2

\#4: (Fracture*[TW] AND (ankle[TW] OR malleol*[TW] OR unimalleo*[TW] OR bimalleo*[TW] OR trimalleo*[TW] OR potts[TW] OR weber[TW] OR (distal[TW] AND (tibia*[TW] OR fibula*[TW]))))

\#5: \#3 OR \#4

\#6: Randomized Controlled Trial[PT]

\#7: Controlled Clinical Trial[PT]

\#8: randomized[TIAB]

\#9: placebo[TIAB]

\#10: Clinical Trials as Topic[MeSH: noexp]

\#11: randomly[TIAB]

\#12: trial[TI]

\#13: \#6 OR \#7 OR \#8 OR \#9 OR \#10 OR \#11 OR \#12

\#14: Animals[MeSH] NOT Humans[MeSH]

\#15: \#13 NOT \#14

\#16: \#5 AND \#15 


\section{The Cochrane Library (Wiley Online Library)}

\#1: MeSH descriptor Ankle explode all trees

\#2: MeSH descriptor Ankle Injuries explode all trees

\#3: MeSH descriptor Ankle Joint explode all trees

\#4: (\#1 OR \#2 OR \#3)

\#5: MeSH descriptor Fractures, Bone explode all trees

\#6: MeSH descriptor Fracture Healing explode all trees

\#7: $\mathrm{MeSH}$ descriptor Fracture Fixation explode all trees

\#8: (\#5 OR \#6 OR \#7)

\#9: (\#4 AND \#8)

\#10: (fracture* NEAR/5 (ankle OR malleol* OR unimalleo* OR bimalleo* OR trimalleo* OR potts OR weber OR (distal AND (tibia* OR fibula*)))).ti,ab,kw

\#11: (\#9 OR \#10)

\section{EMBASE}

\section{Elsevier (1974 to June 2010)}

\#1 (('ankle'/exp OR 'ankle fracture'/exp OR 'ankle injury'/exp OR 'ankle dislocation'/exp) AND ('fracture'/exp OR 'fracture healing'/ exp OR 'fracture fixation'/exp OR 'joint injury'/exp OR 'bone injury'/exp)) OR ((fracture* AND (ankle* OR malleol* OR unimalleo* OR bimalleo* OR trimalleo* OR potts OR weber OR (distal AND (tibia* OR fibula*)))) AND $[<1950-2009] /$ py)

\#2 (('crossover procedure'/exp OR 'double blind procedure'/exp OR 'randomized controlled trial'/exp OR clinical trial'/exp OR single blind procedure'/exp OR placebo'/exp) OR (random* OR factorial* OR crossover* OR 'cross over' OR placebo* OR 'double blind' OR 'single blind' OR assign* OR allocate* OR volunteer*)) AND [<1950-2009]/py)) AND ('human'/exp)

\#3 \#1 AND \#2

\section{Ovid (January 2010 to February 2012)}

exp Ankle Dislocation/ or exp Ankle Injury/ or exp Ankle/ or exp Ankle Fracture/

exp Fracture Healing/ or exp Fracture/ or exp Fracture Fixation/ or exp Joint Injury/ or exp Bone Injury/

1 and 2

(ankle* or malleol* or unimalleo* or bimalleo* or potts or weber or (distal and (tibia* or fibula*))).tw.

fracture*.tw.

4 and 5

3 or 6

Randomized Controlled Trial/

Clinical Trial/

10 Controlled Clinical Trial/

11 Randomization/

12 Single Blind Procedure/

13 Double Blind Procedure/

14 Crossover Procedure/

15 Placebo/

16 Prospective Study/

17 ((clinical or controlled or comparative or placebo or prospective $\$$ or randomi\#ed) adj3 (trial or study)).tw.

18 (random\$ adj7 (allocat\$ or allot\$ or assign\$ or basis\$ or divid\$ or order\$)).tw.

19 ( $\operatorname{singl} \$$ or doubl\$ or trebl\$ or tripl\$) adj7 (blind\$ or mask\$)).tw.

20 (cross?over\$ or (cross adj1 over\$)).tw.

21 ( (allocat\$ or allot\$ or assign\$ or divid $\$$ ) adj3 (condition\$ or experiment $\$$ or intervention $\$$ or treatment $\$$ or therap\$ or control\$ or group\$)).tw.

22 RCT.tw.

23 or/8-22

Surgical versus conservative interventions for treating ankle fractures in adults (Review) 
24 Case Study/ or Abstract Report/ or Letter/

2523 not 24

$26 \quad 7$ and 25

27 (2010\$ or $2011 \$$ or $2012 \$)$.em.

$28 \quad 26$ and 27

29 limit 28 to human

\section{CINAHL (EBSCO)}

S1: (MH “Fracture Healing”) OR (MH “Fracture Fixation”) OR (MH “Ankle Fractures”) OR (MH “Fibula Fractures")

S2: (MM “Ankle”) OR (MH “Ankle Injuries") OR (MH “Ankle Joint”)

S3: S1 AND S2

S4: (fracture* AND (ankle* OR malleol* OR unimalleo* OR bimalleo* OR trimalleo* OR potts OR weber OR (distal AND (tibia* OR fibula*))))

S5: S3 OR S4

S6: (MH "Clinical Trials")

S7: (MH "Evaluation Research")

S8: (MH "Comparative Studies")

S9: (MH "Crossover Design")

S10: PT clinical trial

S11: S6 OR S7 OR S8 OR S9 OR S10

S12: TX ((clinical OR controlled OR comparative OR placebo OR prospective OR randomi*ed) AND (trial OR study))

S13: TX (random* AND (allocate* OR allot* OR assign* OR basis* OR divid* OR order*))

S14: TX ((singl* OR doubl* OR trebl* OR tripl*) AND (blind* OR mask*))

S15: TX (cross* over* OR (cross AND over*))

S16: TX ((allocat* OR allot* OR assign* OR divid*) AND (condition* OR experiment* OR intervention* OR treatment* OR therap* OR control* OR group*))

S17: S12 OR S13 OR S14 OR S15 OR S16

S18: S11 OR S17

S19: S5 AND $S 18$

\section{H IS T O R Y}

Protocol first published: Issue 4, 2010

Review first published: Issue 8, 2012

\section{CONTRIBUTIONS OF AUTHORS}

CD produced the first drafts of the protocol, search strategy and review. HA assisted with the search strategy. CL provided statistical feedback. All authors contributed to subsequent drafts of the protocol and review and approved the final versions. CD is the guarantor of the review. 


\section{DECLARATIONSOF INTEREST}

None known.

\section{SOURCES OF SUPPORT}

\section{Internal sources}

- Luton and Dunstable NHS Trust, London, UK.

Salary for healthcare activities and training medical students and residents

- St. Elisabeth Hospital, Tilburg, Netherlands.

Salary for healthcare activities and training medical students and residents

- St. Radboud University Medical Centre, Nijmegen, Netherlands.

Salary for healthcare activities and training medical students and residents

\section{External sources}

- No sources of support supplied

\section{NDEX TERMS}

\section{Medical Subject Headings (MeSH)}

Ankle Injuries [surgery; * therapy]; Fracture Fixation [methods]; Fractures, Bone [surgery; *therapy]; Randomized Controlled Trials as Topic; Treatment Outcome

\section{MeSH check words}

Adult; Female; Humans; Male 